\title{
Chewing gum and human hair as retrospective dosimeters
}

\author{
Axel Israelsson
}

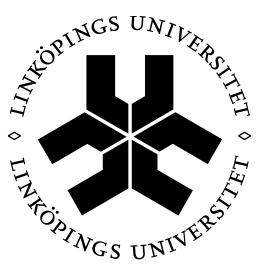

\section{Linköping University \\ FACULTY OF HEALTH SCIENCES}

\author{
Radiation Physics \\ Division of Radiological Sciences \\ Department of Medical and Health Sciences \\ Faculty of Health Sciences \\ Linköping University, Sweden
}

Stockholm, June 2014 
This work was kindly supported in part by funding from the Swedish Radiation Safety Authority (SSM), the Medical Research Council of Southeast Sweden (FORSS) and Linköping University.

Chewing gum and human hair as retrospective dosimeters

Linköping University Medical Dissertations No. 1408

Published articles have been reprinted with permission from the respective copyright holder:

Paper I: Oxford University Press

Paper II: Wolters Kluwer Health Lippincott Williams \& Wilkins

Copyright (C) 2014 by Axel Israelsson.

Division of Radiological Sciences

Department of Medical and Health Sciences

Linköping University

SE-581 85 Linköping Sweden

ISBN 978-91-7519-305-2

ISSN 0345-0082

Cover design: Nora Ahlenius

Printed by LiU-Tryck Linköping, Sweden, 2014 


\section{Abstract}

Retrospective dosimeters are sometimes needed after radiological/nuclear (RN) exposures to determine the doses to individuals. Conventional dosimeters may not be at hand or may not be applicable calling for alternative materials.

The possible exposure situations can be divided into external and internal; the radiation field stems either from outside the body or from a source within. This thesis investigates the possibility to use chewing gum and hair as retrospective dosimeters. The chewing gum would be used after an unexpected radiation event of external type whereas human hair is examined after chronic intake of uranium. Chewing gum containing xylitol and sorbitol was analyzed using electron paramagnetic resonance (EPR) and the hair was analyzed by alpha-spectrometry following radiochemistry and by synchrotron radiation microbeam x-ray fluorescence (SR $\mu$-XRF).

Xylitol and chewing gum (in this particular case, V6) are in the present work found to be valuable dosimeters after unexpected radiation events. The xylitol signal linearity with dose in the interval $0-10$ Gy was confirmed $\left(r^{2}=1.00\right)$. The doses to the coating of the chewing gums were determined 4-6 days after irradiation with an uncertainty of less than 0.2 Gy (1 SD). Spectral dependence with time after exposure was found, but was, however, minimal between 4-8 days.

Hair was evaluated and compared with urine as biodosimeter after ingestion and inhalation intake of uranium. Concentrations of ${ }^{234} U$ and ${ }^{238} U$ and their activity ratios were measured in the hair, urine and drinking water sampled from 24 drilled bedrock well water users in Östergötland, Sweden, as well as among 8 workers at a nuclear fuel fabrication factory, Westinghouse Electric Sweden. The results show that there is a stronger correlation between the uranium concentrations in the drinking water of the well water and the users' hair $\left(r^{2}=0.50\right)$ than with their urine $\left(r^{2}=0.21\right)$. There is also a stronger correlation between the ${ }^{234} U{ }^{238} U$ activity ratios of water and hair $\left(r^{2}=0.91\right)$ than between water and urine $\left(\mathrm{r}^{2}=0.56\right)$. The individual absorbed fraction of uranium, the $f$ value, calculated as the ratio between the excreted amount of uranium in urine and hair per day and the daily drinking water intake of uranium stretched from 0.002 to 0.10 with a median of 0.023 . The uranium concentrations of the fuel factory workers' hair and urine were also obtained as well as that of personal air sampler (PAS) filters for the determination of inhaled uranium activity. A large day-to-day variation (7-70 Bq d $\mathrm{d}^{-1}$ ) of the inhaled ${ }^{234} U$ activity was seen over a 6 week period. Over a 12 week period the ${ }^{234} U$

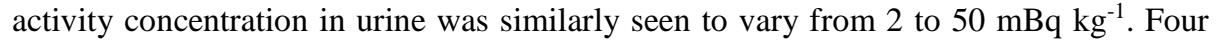
hair samples from the same subject and period showed less variation $\left(100-240 \mathrm{mBq} \mathrm{g}^{-}\right.$ ${ }^{1}$ ). The uranium inhalation to urine and hair factors $f_{i n h, u}$ and $f_{i n h, h}$ were found to be 0.0014 and 0.0002 respectively given by calculations based on the measured PAS, urine and hair data from two individuals. The SR $\mu$-XRF measurements showed that uranium 
is present in an outer layer of the hair shaft, about 10-15 $\mu$ m wide. The measurements also revealed particles containing uranium being present on the surface of unwashed hair shafts. However, the washed hair shafts showed few, if any, particles.

This thesis concludes that chewing gum and hair can be used as retrospective dosimeters after external radiation and after intake of uranium respectively. 


\section{List of publications}

This thesis is based on the following papers, which will be referred to by their capital Roman numerals in the text.

I. Dose response of xylitol and sorbitol for EPR retrospective dosimetry with applications to chewing gum

A. Israelsson, H. Gustafsson and E. Lund

Radiation Protection Dosimetry (2013), Vol. 154, No. 2, pp. 133-141

II. Measurements of ${ }^{234} \mathrm{U}$ and ${ }^{238} \mathrm{U}$ in hair, urine and drinking water among drilled bedrock well water users for the evaluation of hair as a biomonitor of uranium intake

A. Israelsson and H.B.L Pettersson

Health Physics Journal (2014), Vol. 107, No. 2, pp. 143-149

III. Using hair as a bioindicator for inhalation of uranium: A study on nuclear fuel fabrication workers

A. Israelsson and H.B.L Pettersson

In manuscript

IV. On the distribution of uranium in hair: Non-destructive analysis using SR $\mu$ XRF

A. Israelsson, M. Eriksson and H.B.L Pettersson

In manuscript 


\section{Abbreviations}

AMAD activity median aerodynamic diameter

AMS accelerator mass spectrometry

ANKA Angstromquelle Karlsruhe

ARS acute radiation syndrome

CRL compound refractive lens

EPR electron paramagnetic resonance

FLUO X-ray fluorescence beamline at ANKA storage ring

HATM human alimentary tract model

HRTM human respiratory tract model

GI gastro intestinal

IAEA International Atomic Energy Agency

ICP-MS Inductively coupled plasma mass spectrometry

ICRP International Commission on Radiological Protection

IMBA integrated modules for bioassay analysis

IRMM Institute for Reference Materials and Measurements

LA laser ablative

NIST National Institute of Standards and Technology

OSL optically stimulated luminescence

PAS personal air sampler

PtP peak to peak

RIS radiation induced signal

RN Radiological/nuclear

ROI region of interest

SD standard deviation

SEM scanning electron microscope

SR synchrotron radiation

SSM Swedish Radiation Safety Authority (Strålsäkerhetsmyndigheten)

TBP tributyl phosphate

TIMS thermal ionization mass spectrometry

TLD thermoluminescence dosimetry

UV ultra violet

$\mu$-XRF microbeam X-ray fluorescence 


\section{Table of Contents}

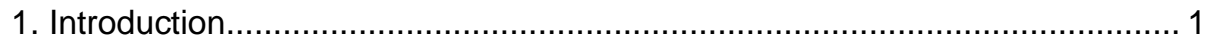

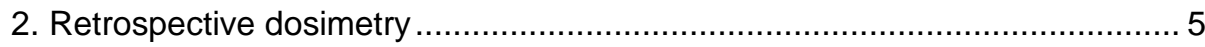

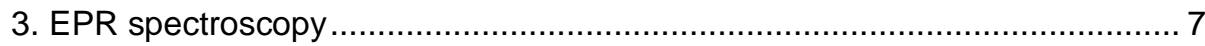

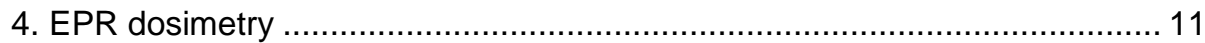

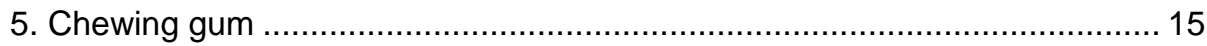

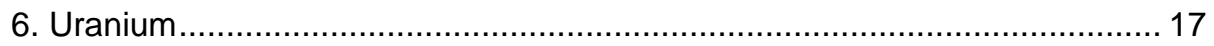

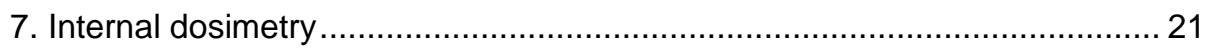

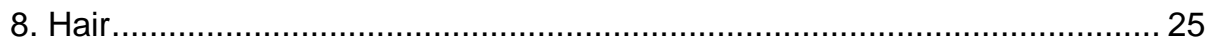

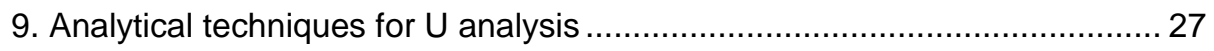

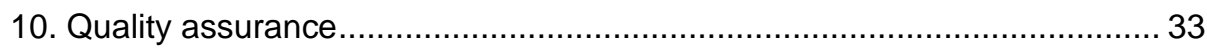

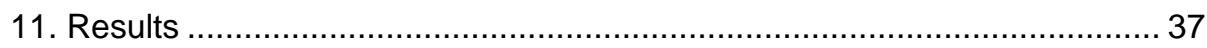

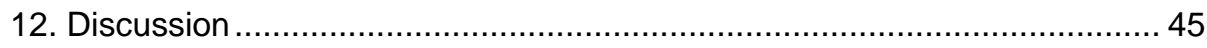

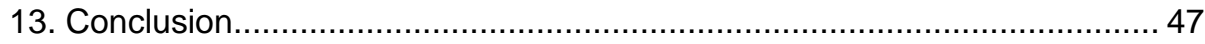

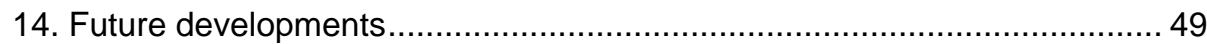

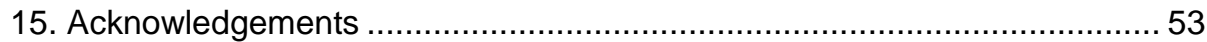

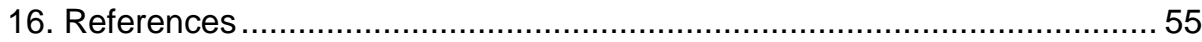





\section{Introduction}

Ionizing radiation is beneficial to humans in for instance the medical field (diagnosis and therapy) and for the commercial production of electricity by nuclear power. However, it is also associated with health risks and therefore needs to be controlled and monitored. In some exposure situations conventional dosimeters are not available or are not appropriate for the monitoring of radiation dose. In these cases, the exposure must be assessed afterwards using other methods. This is referred to as retrospective dosimetry.

Methods of retrospective dosimetry vary and depend on whether people are exposed to internal radiation, i.e. from intake of radionuclides, or if they are exposed to external radiation. Exposure from internal contamination has usually been assessed using samples of blood, urine and feces. Exposure to external radiation is retrospectively determined through physical methods or biological methods.

EPR dosimetry is a common retrospective method used to derive doses in biological materials such as tooth enamel, nails and bone and materials such as sugar, glass and clothing fabrics that are often carried by people. The dosimetric properties of these and new potential dosimeter materials are evaluated in order to make accurate dose determinations when retrospective dosimetry is called for. Optimally, the material should have high radiation-induced signal specificity, a low background signal, a low UV-induced signal, a low detection limit and linearity of the signal with dose (Trompier et al. 2009).

Several kinds of sugar have been tested as retrospective dosimeters (Sagstuen et al. 1983, Nakajima 1994, Hutt et al. 1996, Shiraishi 2002, Hervé 2006). However, nowadays other artificial sweetening agents are frequently used in products typically carried by people. Xylitol and sorbitol are two common sweeteners often found in chewing gum and candy. It is of interest to study the radiation-induced EPR signal in these sweeteners and investigate the possibility of using them for accidental and retrospective dosimetry. 
Intake of uranium is natural since food products and drinking water contain uranium, but normally in low concentrations. Elevated levels of uranium are, however, found in the water of drilled bedrock wells, resulting in significant intakes for its users (Isam Salih et al. 2002, Muikku et al. 2009).

In the nuclear industry uranium may be inhaled or ingested in uranium mining, fuel enrichment and fabrication predominantly as chronic low level exposures but potentially also as accidental high exposures. Urine analysis is the common method to evaluate uranium intake and body burden. Lately, hair has been studied as biomonitor after intake of uranium by ingestion (Gonnen et al. 2000, Mohagheghi et al. 2005, Karpas et al. 2005a), but has, to the best of our knowledge, not been evaluated as a biomonitor after inhalation intakes.

After uranium ingestion, chemical toxicity of the kidneys is the main risk factor, but the major risk of health effects after inhalation of uranium stem from the alpha irradiation of the lung tissue. The total uranium activity intake is highly dependent on the ${ }^{234} U /{ }^{238} U$ activity ratio.

As for enriched uranium used in the nuclear industry, ${ }^{234} \mathrm{U} /{ }^{238} \mathrm{U}$ activity ratios of up to 8 is common, resulting in total uranium activity concentrations about four times higher than corresponding for the same mass amount of natural uranium. The fraction of natural and enriched uranium as in a mixed intake can be determined from the ${ }^{234} \mathrm{U} /{ }^{238} \mathrm{U}$ and/or ${ }^{235} U /{ }^{238} U$ activity ratios and thus be used as signatures of the exposure. After chronic intake of uranium, hair may be a good complement to urine as it reflects uranium excretion of time periods of days up to several months.

The distribution of uranium in single hair shafts can yield important information on how the measured concentrations should be interpreted. Longitudinal scans of hair strands using laser ablative inductively coupled plasma mass spectrometry (LA ICP-MS) have shown promising results for the purpose of chronological assessments (Elish et al. 2007). However, with a spatial resolution down to a few $\mu \mathrm{m}, \mathrm{SR} \mu$-XRF may be used to detect uranium fragments of $\mu \mathrm{m}$ size and also provide information on the latitudinal distribution in the shafts. This technique is non-destructive and thus allows for subsequent analysis of the hair shafts by other methods.

\section{Aims}

The aim of this thesis was to evaluate hair and chewing gum for their use as retrospective dosimeters. While hair is evaluated as a monitor of internal chronic exposure, the chewing gum is evaluated for the use as an accidental dosimeter following external irradiation. 
The purpose of Paper I was to study the radiation-induced EPR signal in sweeteners xylitol and sorbitol for use in retrospective dosimetry.

The purpose of Paper II was to evaluate scalp hair and compare it with urine as a biomonitor for intake of uranium by ingestion. Concentrations of ${ }^{234} U$ and ${ }^{238} U$ and their activity ratios were measured in hair, urine and drinking water of 24 drilled bedrock well water users in Östergötland, Sweden.

The purpose of Paper III was to evaluate scalp hair and compare it with urine as a potential biomonitor following intake of uranium by inhalation. Concentrations of ${ }^{234} \mathrm{U}$ and ${ }^{238} \mathrm{U}$ and their activity ratios were measured in hair, urine, PAS-filters and drinking water among eight workers at a nuclear fuel fabrication factory.

In Paper IV the distribution of uranium in single human hair shafts was evaluated using two synchrotron radiation based micro X-ray fluorescence techniques; SR $\mu$-XRF and confocal $\mu$-XRF. 



\section{Retrospective dosimetry}

Retrospective dosimetry has been defined as "The estimation of a radiation dose received by an individual recently (within the last few weeks), historically (in the past) or chronically (over many years)" (Ainsbury et al. 2011). Several methods are in use. Depending on the exposure and situation some are more suitable than others. They are often divided into biological and physical methods.

The biological methods are based on analyses of living matter. They include haematologic, cytogenetic, genetic and protein biomarker techniques. These methods have the advantages that they provide the actual body alterations and thereby take the individual dose sensitivity into consideration. The physical methods are not necessarily used on body materials (e.g. tooth enamel, bone, hair nails) but can also be used on carried personal belongings (e.g. mobile phones, watches, sweets). The most common physical methods are EPR dosimetry (described in the next section), dosimetry based on thermoluminescence (TLD) and dosimetry based on optically stimulated luminescence (OSL). Both TL and OSL dosimeters measure the amount of electron-hole pairs that is formed and trapped upon radiation exposure. The main difference is in the de-trapping process. While OSL-dosimeter de-trapping is performed optically with lasers, TL dosimeter detrapping is achieved by heating.

Radiometry on human tissue or excreta for the assessment of internal exposure is not traditionally associated with retrospective dosimetry. Nevertheless, quantification of radioactive elements in urine is routinely performed after suspected internal contamination of beta- or alpha emitting radionuclides, e.g. in the nuclear industry. Blood, hair and nails have also been used but to a lesser extent. The most common quantification methods include alpha/beta spectrometry, inductively coupled plasma mass spectrometry (ICP-MS), scanning electron microscope (SEM) and X-ray fluorescence (XRF). 



\section{EPR spectroscopy}

EPR spectroscopy is used to analyze the composition of materials with paramagnetic compounds. When applying an external magnetic field, $B$, over a material sample, the magnetic moment of paramagnetic centra such as unpaired electrons tend to align with it. By then irradiating the sample with microwave photons, absorption of the photons may occur causing the magnetic moment of the centra to flip in spin up/down state and align opposite with the field. This is known as resonance and occurs when the energy of the microwaves match the energy difference of the spin up and down states, i.e. $h v=$ $\Delta E$. The energy difference, $\Delta E$, is proportional to $B$. Different applied magnetic field values will cause absorption of the microwaves due to the magnetic properties of the surrounding of the centra. Information about the material composition can thereby be obtained by analyzing the absorption of the microwaves with respect to the applied magnetic field.

In continuous wave EPR the microwave frequency is fixed and the magnetic field is swept. The magnetic field is also modulated and the absorption is detected with a frequency that equals the modulation frequency in order to discriminate noise. The acquired EPR spectrum is given as the derivative of the absorption in respect to the magnetic field, due to this modulation as is shown in figure 1. EPR spectra generally show the first derivative of the absorption. In theory the double integral of the output signal would give a measure of the amount of paramagnetic centra in the sample, but for relative quantification of the radical density it has been shown that measuring the difference between the maximum and minimum value, i.e. the peak-to-peak value, of the derivative spectrum is a good measure of the paramagnetic centre density (Ahlers and Schneider 1991). The main problem of double integrating comes with the variation of the base line between measurements due to spectrometer drifting. 


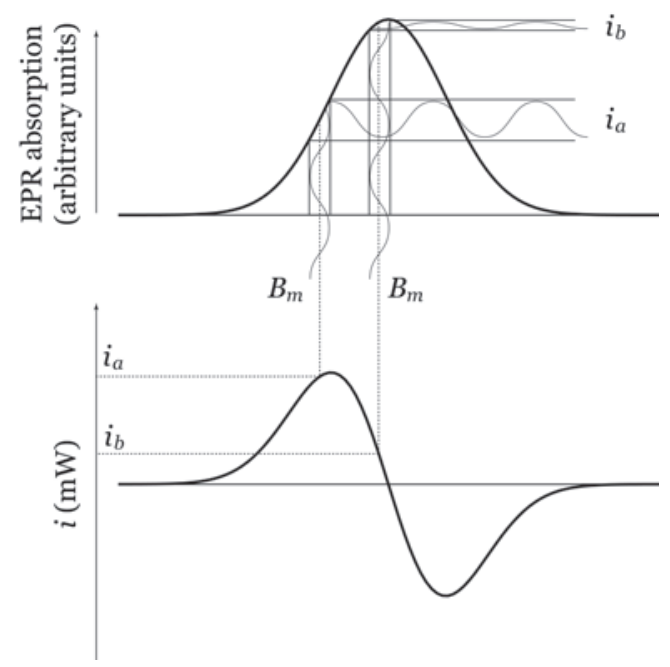

Figure 1. The upper graph shows the absorption to magnetic field while the lower shows the derivative. The field modulation, $B_{m}$, and frequency are constant. The detector is set to only record signals (absorption) varying with this frequency. The amplitude of this signal, $i$, will approximate the derivative of the absorption spectrum (Gustafsson 2008).

The choice of modulation amplitude is important when acquiring the EPR spectrum. Higher modulation amplitude yields a higher signal to noise ratio, whereas a lower results in a better spectral resolution. Hence, with lower modulation amplitude, peaks may be resolved but the signal to noise ratio may be too low to use for peak measurements. In figure 11, the modulation amplitude was fairly low $(0.2 \mathrm{mT})$ enabling several peaks to be observed. Figure 2, on the other hand, shows an EPR spectrum acquired with 1.25 $\mathrm{mT}$ and several peaks are now integrated into two large peaks. 


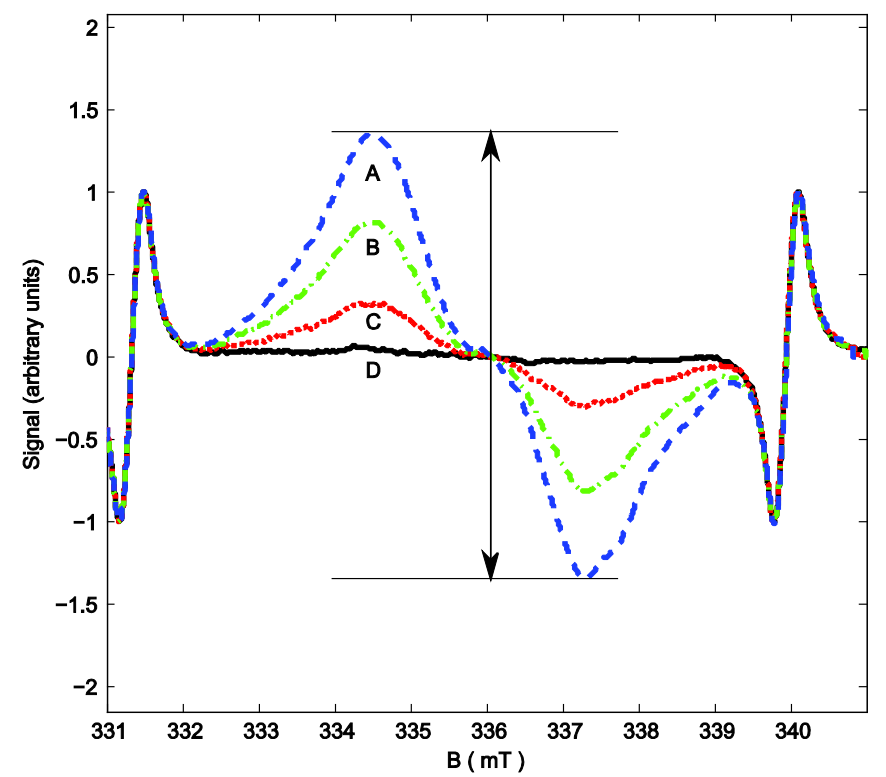

Figure 2. Sucrose EPR spectra. EPR signal as a function of applied magnetic field. Given doses are $A=14 \mathrm{~Gy}, \mathrm{~B}=8 \mathrm{~Gy}$, $\mathrm{C}=3 \mathrm{~Gy}$ and " $\mathrm{D}$ " is unirradiated. The peak-to-peak value of spectrum " $\mathrm{A}$ " is shown by the double arrow.

In figure 2 typical EPR spectra are shown. $\mathrm{Mn}^{2+} / \mathrm{MgO}$ is often used as reference for the magnetic field value and sometimes also for signal intensity, as it has well defined magnetic properties. In the figure the $\mathrm{Mn}^{2+}$ peaks are located to the far right and far left. 



\section{EPR dosimetry}

Free radicals are created in most interactions between ionizing radiation and materials. Normally these are very reactive and recombine with surrounding molecules in a short period of time. However, in crystalline materials they can be trapped and long-lived (sometimes almost stable). EPR dosimetry is an established non-destructive method which uses EPR spectroscopy to determine the dose to materials by quantifying the free radicals created upon irradiation.

Alanine and lithium formate have been used as dosimeters for applications in radiation therapy as they have high sensitivity to radiation. Other materials such as tooth enamel, bone, nails and mobile phone glass with lower sensitivity have been used in retrospective dosimetry, where the required dose precision is not as high. Different kinds of sugars have also been studied for the purpose of retrospective dosimetry (Nakajima 1995, Hervé 2006, Hervé et al. 2006). Hervé characterized dosimetric properties of ascorbic acid, sorbitol, glucose, galactose, fructose, mannose, lactose and sucrose. However, sweetening agent xylitol, nowadays commonly used in chewing gums world-wide and known for its caries preventing effects has not before been evaluated for its use as a retrospective dosimeter material nor have the products containing it.

Since not only ionizing radiation can give rise to paramagnetic centra in a material, it can be complicated to distinguish the radiation induced signal (RIS). The spectra often consist of several peaks with large line widths overlapping each other. Furthermore, the peak-to-peak signal needs to be calibrated with respect to the absorbed dose. It is usually done using the calibration curve method or by the additive dose method, as described in an IAEA report (2002) for tooth enamel dosimetry. In the additive method, the same samples are used for calibration and measurement. Controlled exposures and subsequent read-outs are then performed before or after the measurement. For retrospective dosimetry the calibration can only be done afterwards. The additive method requires that the unexposed signal of the analyzed material is known or known to be negligible. The cal- 
ibration curve method makes use of a separate reference sample that is calibrated instead of the dosimeter sample. This requires that the reference and dosimeter samples are identical.

In the present thesis, the calibration curve method was used. As the spectra of the investigated materials were found to vary with time after exposure it would have been complicated to evaluate the peak-to-peak signal from multi-exposed spectra irradiated at different time points. The calibration curve, figure 3, instead consisted of two calibration points, of which one was unirradiated. The use of only two calibration points required complementing analyses of the dose linearity in the measured interval. The signal linearity with dose for xylitol and sorbitol is shown in figure 4.

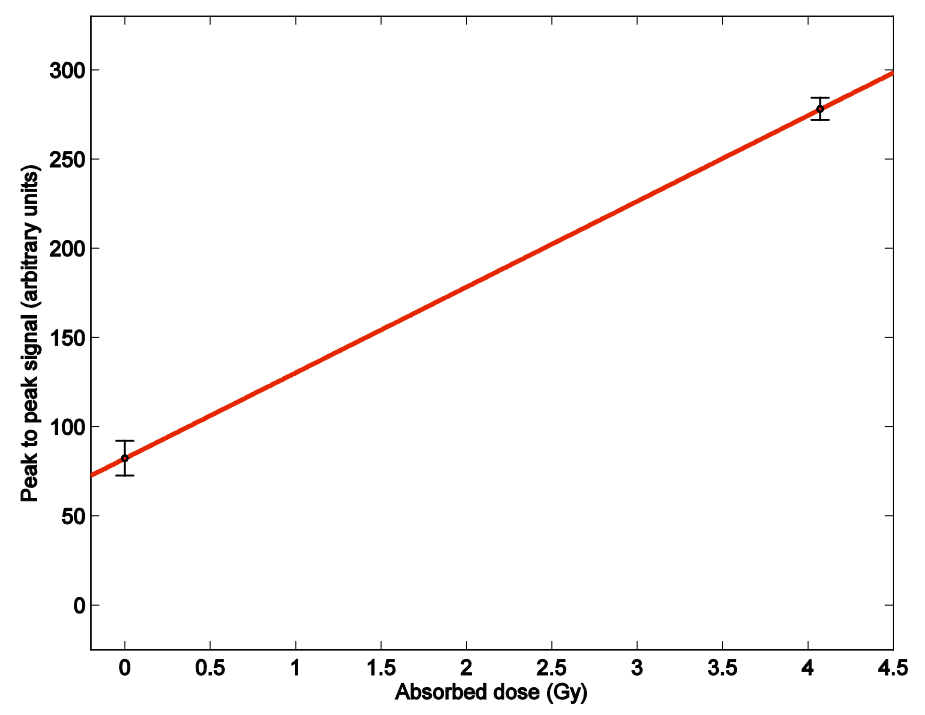

Figure 3. Calibration curve for V6 chewing gum. 


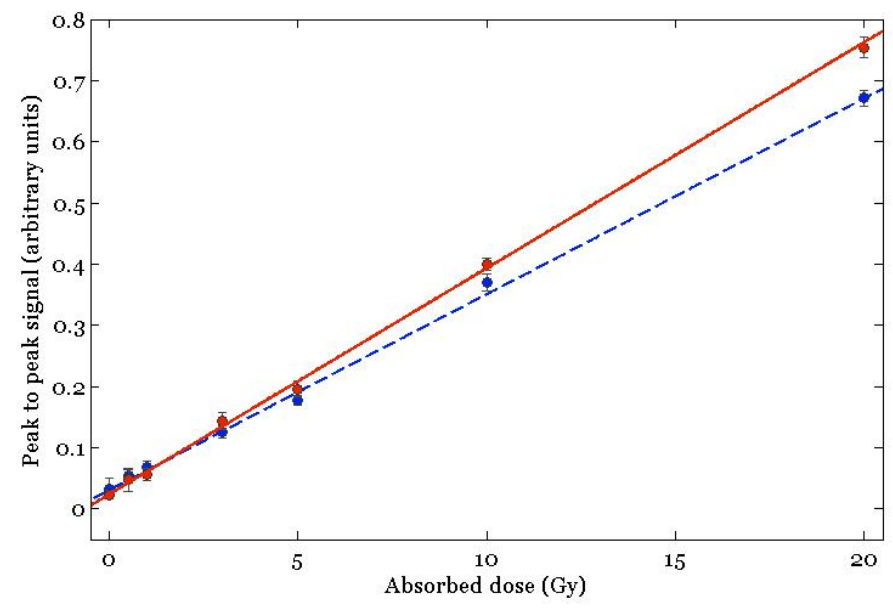

Figure 4. Dose response linearity of xylitol (red, solid line) and sorbitol (blue, dashed line).

\section{A fatal accident}

Sugars have been used for retrospective dosimetry after fatal accidents in Norway and Estonia (Sagstuen et al. 1983, Hutt et al. 1996). In the Norwegian accident a radiation worker was exposed while repairing a ${ }^{60} \mathrm{Co}$ source used for radiation processing. The source of $2.4 \mathrm{PBq}\left(2.4 \times 10^{15} \mathrm{~Bq}\right)$ was apparently unshielded while the work was done. After 20 minutes the worker complained of feeling sickness. It was later found to be acute radiation syndrome, but it was initially suspected that it was a heart disease. Due to a medical history of heart disease, the victim carried nitroglycerin tablets containing lactose and sorbitol. These were analyzed using EPR and it was found that the radiation worker had been exposed to $38 \mathrm{~Gy}$. He passed away 13 days after exposure (Regulla and Deffner 1989). 



\section{Chewing gum}

Chewing gums have been used by humans for at least 3000 years and are nowadays chewed worldwide. They usually consist of a gum base, sweeteners and flavoring. A common chewing gum model is displayed below in figure 5. It has the gum base located centrally inside the coating, which contains the bulk of the sweetening. That allows for mechanical separation of the coating from the gum.

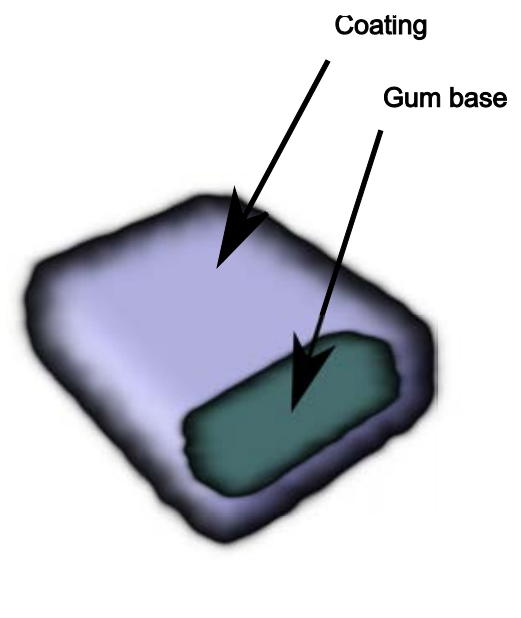

Figure 5. Chewing gum with gum base and coating. The sweetening agent is mainly located in the coating.

\section{Chewing gum as a retrospective dosimeter}

Chewing gum is in paper I found well suited as a retrospective dosimeter after some specific exposure scenarios. However, only external radiation is monitored. It should be used when conventional dosimeters with higher precision aren't available. 
A possible scenario in which chewing gum could be used as a retrospective dosimeter is when radioactivity is dispersed in public. Terror attacks may involve bombs to hurt and kill people. It is usually well-covered in media and the fear itself and threat of additional attacks can paralyze parts of the population linked to the area of the blast. If radioactive materials are incorporated in the bomb and spread out with the blast the physical harm may increase as the number of injured and killed may increase. Furthermore, the psychological harm is magnified as the fear of radiation exposure may paralyze many more people than those directly affected by the bomb. Consequently, a large number of people with worries of being exposed may need to be examined in terms of received dose (NCRP 2001).

Swartz et al. (2011) has defined four areas of use for which retrospective dosimeters are needed after an unexpected radiation event. (i) Triaging after a large scale event, (ii) guiding medical management after a large scale event, (iii) guiding medical management after a small scale event and (iv) determining long-term consequences of the exposure. The four areas have different requirements. For example, triaging after a large scale event needs simple and quick sample collection and handling so that many people can be assessed in a short amount of time. In a triage of a large event, people receiving whole body doses higher than about 1 Gy are in need of medical care for the risk of acute radiation syndrome (ARS). For medical guidance after large scale events a maximum required dose uncertainty of $0.25-0.5 \mathrm{~Gy}$ is proposed. The determining of longterm consequences, however, needs to be determined with a precision of about $20 \mathrm{mGy}$.

\section{Dose reconstruction}

When carried by individuals chewing gums can be assumed to have materials covering them. In the event of $\gamma$-irradiation with energies up to $\mathrm{MeV}$ level, which is believed to be a probable type of exposure, these covering materials can provide enough secondary electrons to give a homogenous dose distribution in the chewing gum coating. Secondary electrons of $500 \mathrm{keV}$ have a range of about $0.19 \mathrm{~g} / \mathrm{cm}^{2}$ in cellulose, and, as an example, clothes with a density of e.g. $0.3 \mathrm{~g} / \mathrm{cm}^{3}$ need to be thicker than $0.6 \mathrm{~cm}$ to allow a homogenous dose distribution of the chewing gum. Fabrics, papers or plastics are also probable cover materials.

The determined dose of the chewing gum coating could ideally be used to estimate the effective dose. However, this requires an even whole body exposure. If information about the exposed people's positions relative to the radiation source can be obtained, it may be possible to make dose estimations also of exposed people not carrying chewing gums. At many sites there are surveillance cameras that can provide this information. Having several persons carrying potential dosimeter materials more detailed dose reconstructions can be performed. 


\section{Uranium}

Uranium is a primordial alpha-emitting heavy metal which occurs naturally at ppm levels in soil, rock and water, and at higher levels in e.g. granite and pegmatite rocks. Uranium is primarily used in the society for its fissional qualities as fuel to produce nuclear power, but also in the military sector as a component in nuclear weapons and in munitions and armors (depleted uranium). However, the main health concerns regarding uranium are not associated with it being fissional, but rather with its alpha-decay and its chemical toxicity.

Natural uranium consists of three isotopes; ${ }^{238} U$ and ${ }^{234} U$, belonging to the uranium decay series and ${ }^{235} \mathrm{U}$ from the actinium decay series. The relative isotope mass fractions in undisturbed natural systems are $99.27 \%\left({ }^{238} U\right), 0.0055 \%\left({ }^{234} U\right)$ and $0.72 \%\left({ }^{235} U\right)$, resulting in relative activities of $48.9 \%, 48.9 \%$ and $2.2 \%$, respectively ( $1 \mathrm{ppm}$ natural uranium (1 mg U kg${ }^{-1}$ ) corresponds to $12.4 \mathrm{~Bq} \mathrm{~kg}^{-1}$ of each ${ }^{238} \mathrm{U}$ and ${ }^{234} \mathrm{U}$ and $0.57 \mathrm{~Bq}$ $\mathrm{kg}^{-1}$ of ${ }^{235} \mathrm{U}$ ). However, in the environment and in particular in ground water, fractionation of the ${ }^{234} U$ isotope may occur, resulting in non-secular equilibrium conditions (see next section).

In the nuclear industry, where enriched uranium is used, ${ }^{235} \mathrm{U}$ is typically enriched 4-7 times, i,e. to 3-5 mass-\% relative ${ }^{238} U$. In the process ${ }^{234} U$ will also be enriched, approximately at the same magnitude (4-7 times). The by-products from the enrichment process contains uranium that is depleted of ${ }^{234} U$ and ${ }^{235} U$, typically $<0.001 \%{ }^{234} U$ and $0.2 \%{ }^{235} \mathrm{U}$.

In table 1 , half-life, alpha energies and probabilities for the most common $\alpha$-emissions are listed. ${ }^{232} \mathrm{U}$ is included as it is often used as a yield determinant in radiochemical separation of uranium. 


\begin{tabular}{|c|c|c|c|}
\hline Isotope & $\begin{array}{c}\text { Half-life } \\
\text { (years) }\end{array}$ & $\begin{array}{c}\alpha \text { - probability } \\
\text { (\% per decay) }\end{array}$ & $\begin{array}{c}\alpha \text { - energy } \\
\text { (MeV) }\end{array}$ \\
\hline${ }^{232} \mathrm{U}$ & 68.9 & 68 & 5.32 \\
& & 32 & 5.26 \\
\hline${ }^{234} \mathrm{U}$ & $2.46 \cdot 10^{5}$ & 71 & 4.77 \\
& & 28 & 4.72 \\
\hline${ }^{235} \mathrm{U}$ & $7.04 \cdot 10^{8}$ & 60 & 4.40 \\
& & 17 & 4.37 \\
\hline${ }^{238} \mathrm{U}$ & $4.47 \cdot 10^{9}$ & 79 & 4.20 \\
& & 21 & 4.15 \\
\hline
\end{tabular}

Table 1. The half lives of the natural uranium isotopes and ${ }^{232} \mathrm{U}$ and their most common $\alpha$-emissions.

\section{Natural environment}

\section{In soil}

The concentrations of uranium in soils vary considerably depending on the local geology. Relatively low concentrations (sub-ppm) are found in basic rocks like basalts, higher in acid sedimentary rocks and still higher concentrations in granites and pegmatites, up to \%-levels. A global median ${ }^{238} \mathrm{U},{ }^{234} \mathrm{U}$ concentration of $35 \mathrm{~Bq} \mathrm{~kg}$ (about $3 \mathrm{ppm}$ ) is given by UNSCEAR (2000) for soil.

\section{In water}

The species of uranium found in ground water vary depending on source material, physical and chemical parameters controlling the release, $\mathrm{pH}$ value, reduction potential and the character and flow parameters of aquifers. The main uranyl complexes in groundwater are with fluoride at $\mathrm{pH}=3$ to 4 , phosphate at $\mathrm{pH}=4$ to 7.5 and carbonate above $\mathrm{pH}=$ 7.5 (Ivanovich and Harmon 1982). But at alkaline conditions the uranyl carbonates may form complexes with calcium. Drinking water from drilled bedrock wells in Finland has shown a predominance of calcium uranyl carbonates, $\mathrm{Ca}_{2} \mathrm{UO}_{2}\left(\mathrm{CO}_{3}\right)_{3}$ (Prat et al. 2009).

In ground waters the ${ }^{234} \mathrm{U}$ and ${ }^{238} \mathrm{U}$ are often found in disequilibrium, i.e. ${ }^{234} \mathrm{U} /{ }^{238} \mathrm{U}$ activity ratios higher than unity, due to preferential mobilization of ${ }^{234} U$ to water from rocks. In slow-moving ground waters the activity ratio can reach above 10 (Ivanovich and Harmon 1982). This disequilibrium is explained by the alpha recoil process, i.e. where during the alpha decay the daughter radionuclide will be displaced in the mineral lattice due to the recoil, and therefore become more vulnerable to leaching (Osmond and Cowart 1976). Another possible explanation is higher solubility of the intermediate decay products ${ }^{234} \mathrm{Th}$ and ${ }^{234 \mathrm{~m}} \mathrm{~Pa}$. 
Concentrations of uranium in drinking water show variations of several orders of magnitude, from typically $\mathrm{mBq} \mathrm{kg}{ }^{-1}$ level $\left({ }^{238} \mathrm{U}\right)$ in municipal waters to up to several $\mathrm{Bq} \mathrm{kg}^{1}$ $\left({ }^{238} \mathrm{U}\right)$ in drinking water from private drilled wells. UNSCEAR (2000) propose a global reference value of $1 \mathrm{mBq} \mathrm{kg}^{-1}$ and a recent European study of uranium in foodstuffs and water in 17 countries show a mean ${ }^{238} \mathrm{U}$ concentration of $8 \mathrm{mBq} \mathrm{kg}{ }^{-1}$ (range $0.1-14 \mathrm{mBq}$ $\mathrm{kg}^{-1}\left(5^{\text {th }}-95^{\text {th }}\right.$ percentile) (EFSA 2009). At this concentration the annual committed effective dose is insignificant $(<1 \mu \mathrm{Sv})$.

\section{In air}

Concentrations of uranium in ambient air are normally very low, of the order of 1-20 $\mu \mathrm{Bq} \mathrm{m}^{-3}$ in populated areas (UNSCEAR 2000), resulting in daily intakes of less than 1 $\mathrm{mBq}$, thus contributing very little to the uranium body burden $\left(<0.1 \mu \mathrm{Sv} \mathrm{y}^{-1}\right)$.

\section{Food}

As uranium is present in the soil and water in measurable quantities it will also be found in foodstuffs. UNSCEAR (2000) present uranium data $\left({ }^{238} \mathrm{U},{ }^{234} \mathrm{U}\right)$ for a range of food products (milk, meat, grain, vegetables, fish) with proposed reference values of a few $\mathrm{mBq} \mathrm{kg}{ }^{-1}$ up to $30 \mathrm{mBq} \mathrm{kg}^{-1}$.

From a European study on uranium in foodstuffs (EFSA 2009), in which uranium concentrations of typical food baskets in 17 countries are compiled, one can conclude that intake by water typically contribute more to the total uranium dietary intake than all other foodstuffs together. For a person weighting $70 \mathrm{~kg}$, the tabulated values result in a calculated annual median overall foodstuffs intake of about only $8 \mathrm{~Bq}^{238} \mathrm{U}$.

\section{Health concerns}

Epidemiological studies on intake of naturally radioactive water have shown evidence of uranium nephrotoxicity (Wrenn et al. 1985) and radium bone carcinogenicity (Finkelstein and Kreiger 1996). Animal studies have shown association between uranium in kidneys and renal metabolism of xenobiotics and vitamin D- and ironhomeostasis. Furthermore, uranium-induced oxidative stress and alteration of gene expression in metabolic pathways, cell signaling, and trafficking, has been reported. There is also a documented association between uranium concentration in drinking water and indicators of bone resorption (Canu et al. 2011).

As part of radioactive decay series, uranium is usually accompanied with its decay products in drinking water. Corresponding intake of radium, thorium, polonium and 
radon may contribute more to the radiation dose than uranium (Isam Salih et al. 2002, Jia et al. 2009).

\section{Nuclear industry}

Uranium is processed and handled in all sectors of the nuclear fuel cycle; i.e. in uranium mining, milling, enrichment, fuel fabrication, reactor operations, reprocessing and waste disposal. The impact on the environment, i.e. release to the aquatic and terrestrial environment, has been extensively studied for decades with data compiled by e.g. UNSCEAR (2000). 


\section{Internal dosimetry}

Internal dosimetry is the field of assessing radiation doses to different organs and tissues after intake of radioactive materials. ICRP has established compartment models which describe the transport and retention of radionuclides in the human body. The human alimentary tract model (HATM) is used for intake by ingestion and the human respiratory tract model (HRTM) is used for intake by inhalation (ICRP 1994, ICRP 2006). These models are complemented with a biokinetic model for workers describing the transport and retention of the nuclides after absorption to blood (ICRP 1997). This model includes the excretion to urine and feces but does not include hair as an excretion pathway.

\section{Inhalation}

The HRTM-model describes the rather complex biokinetics of inhalation of aerosols; the morphology and physiology of the respiratory tract, the deposition in different parts of the lung tissue, and the clearance of deposited activity. The extent of deposition is determined by the activity aerodynamic and thermodynamic diameters of the aerosol as well as breathing rate and fraction of nose breathing. Parts of the aerosol entering the respiratory tract are rapidly exhaled and other parts are cleared by mucociliary transport into the GI-tract as well as transported to the regional lymph nodes. The remaining deposited material, in this case uranium particles, is gradually absorbed into blood. However, the rate of absorption into blood is determined by the rate of dissociation/dissolution of the particles which strongly depends of the physical and chemical form of the uranium particles. The ICRP (1994) recommends default values for the absorption of uranium in three classes; (i) Type F (fast); rapid absorption of uranium, halftime about $10 \mathrm{~min}$, used for most hexavalent uranium compounds, e.g. $\mathrm{UF}_{6}, \mathrm{UO}_{2} \mathrm{~F}_{2}$, $\mathrm{UO}_{2}\left(\mathrm{NO}_{3}\right)_{2}$, (ii) Type $\mathrm{M}$ (moderate); $10 \%$ of the activity is absorbed with a half-time of $10 \mathrm{~min}$ and $90 \%$ with a half-time of $140 \mathrm{~d}$, used for less soluble uranium compounds, e.g. $\mathrm{UO}_{3}, \mathrm{UF}_{4}, \mathrm{UCl}_{4},\left(\mathrm{NH}_{4}\right)_{2} \mathrm{U}_{2} \mathrm{O}_{7}$ (ADU), and possibly carbonate complexes, e.g. 
$\mathrm{UO}_{2} \mathrm{CO}_{3} \cdot 2\left(\mathrm{NH}_{4}\right)_{2} \mathrm{CO}_{3}$ (AUC), (iii) Type S (slow); $0.1 \%$ is absorbed with a half-time of $10 \mathrm{~min}$ and $99.9 \%$ with a half-time of $7000 \mathrm{~d}$, used for highly insoluble uranium compounds, e.g. $\mathrm{UO}_{2}, \mathrm{U}_{3} \mathrm{O}_{8}$. This classification and default values are primarily based on experimental animal in vivo data and in vitro dissolution studies, and can be helpful for making rough dose estimates, but it should be remembered that large variations in the absorption and dissolution data can be found in the literature. Among the uranium compounds mentioned above, all types (F, M, S) are present in the nuclear fuel factory processes.

\section{Ingestion}

Uranium that can reach the gastrointestinal tract, either from direct ingestion or indirectly from uranium transported from the respiratory tract, is either absorbed in the small intestine (soluble uranium) or cleared by feces. The fraction absorbed to blood can vary considerably on individual level according to the literature. Zamora et al. 2002 show a range from 0.001-0.08 with a median value of about 0.01. The ICRP (1995) recommends an absorption fraction $f_{1}=0.02$ for unspecified compounds of uranium for workers and members of the public. The remaining $98 \%$ will pass through the GI-tract without absorption and is excreted by feces. For workers the ICRP (1995) also propose a reduced absorption fraction $f_{1}=0.002$, for intakes of most tetravalent uranium compounds; e.g. $\mathrm{UO}_{2}, \mathrm{U}_{3} \mathrm{O}_{8}, \mathrm{UF}_{4}$.

\section{Excretion}

Following absorption of uranium in blood plasma, uranium is further transferred between tissues and organs, as described in the ICRP HATM-compartment model. Part of the uranium is retained by soft tissue and bone, the latter with very long retention times. The bulk of the uranium is, however, transferred back to blood plasma and eventually excreted in urine. The ICRP model does not include hair as an excretion pathway (ICRP 1997, ICRP 2006). A modified compartmental model which includes hair as an excretion pathway has been presented by Li et al. (2009).

\section{Dose assessment}

Assessment of radiation doses to individuals (workers and members of the public) from uranium intake by ingestion or by inhalation could be made by calculations based on dosimetric models, as those of the ICRP, or be estimated based on bioassay sampling of urine or feces. In the case of intake by inhalation the ICRP (2012) provide committed effective dose coefficients, $\mathrm{E}(\tau)$ /activity $\left(\mathrm{Sv} \mathrm{Bq}{ }^{-1}\right)$ for the absorption types (F, M, S) and for activity median aerodynamic diameters (AMAD) of 1 and $5 \mu \mathrm{m}$ respectively. Thus, an estimate of $\mathrm{E}(\tau)$ can be made if the uranium aerosols are characterized in terms of 
activity concentration, absorption type and size distribution, AMAD. Normally, this requires large efforts for continuous sampling and analyses, especially when doses on individual level need to be determined.

In the case of intake by ingestion the ICRP (2012) also provide dose coefficients $\mathrm{E}(\tau)$ /activity $\left(\mathrm{Sv} \mathrm{Bq}{ }^{-1}\right)$, for the absorption types $\mathrm{F} \& \mathrm{M}$. Given that the ingestion intake of uranium and the chemical form of uranium can be estimated/assessed, estimates of $\mathrm{E}(\tau)$ can be made on individual level.

Often the dose assessments for individuals are based on bioassay sampling data, i.e. periodic sampling and analysis of uranium in urine and occasionally in feces. Dose calculations are then based on model calculations, e.g. the ICRP HATM-model. Good knowledge about absorption types is needed as well as aerosol size distribution in the case of uranium inhalation, in order to assess the intake of uranium. As has been discussed in this thesis, since chronic exposure (uranium intake) may vary significantly over time, both for workers and members of the public, periodic sampling of urine may not be sufficient to obtain reliable estimates of the chronic intake of uranium. 



\section{Hair}

The human hair consists of the hair root below the skin surface and the shaft above it, figure 6 . The hair root is situated in the dermis and is at the bottom a bit wider and rounded; the follicle. Embedded by the follicle is the dermal papilla, which has a generous flow of nourishment via the blood stream. Here is where the hair cells are formed. The cells are filled with keratin already below the epidermis, which means that the hair is dead tissue above the skin surface. The hair shaft consists of three layers. Outermost is the cuticle, which is colorless and serves to protect the second layer, the cortex. This middle layer provides strength, color and texture to the hair. The innermost part, the medulla, is only present in thick hairs and sometimes only in segments of single shafts. (Nationalencyklopedin 1992, Follicle 2014)

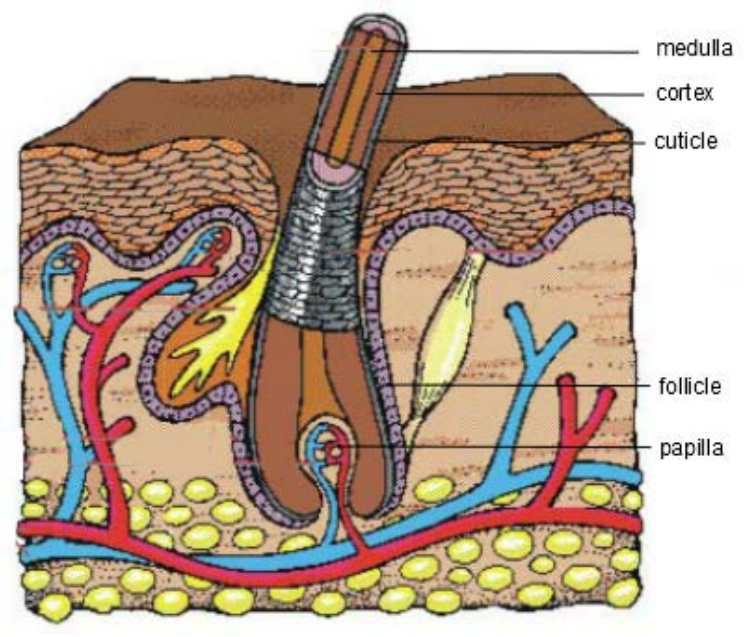

Figure 6. The human hair structure. (Follicle 2014) 



\section{Analytical techniques for $U$ analysis}

Uranium can be quantified and/or its distribution can be obtained from a few different techniques. These include alpha spectrometry, XRF, ICP-MS, accelerated mass spectrometry (AMS), laser-excitation, fission track, n-activation and thermal ionization mass spectrometry (TIMS). In the present work alpha spectrometry was used for quantification of $U$ after radiochemical separation of urine, hair, water and PAS-filter samples while SR $\mu$-XRF scans were used to obtain the distribution in single hair shafts.

\section{Sample preparation}

The sample amounts used for analysis were approximately $1 \mathrm{~kg}$ of water, $0.2 \mathrm{~kg}$ of urine and $0.2 \mathrm{~g}$ of hair. The hair and urine samples were stored frozen and urine and water samples were kept in acidic condition $(0.1 \mathrm{M} \mathrm{HCl})$. All samples were weighed on calibrated laboratory balances. Prior to radiochemical separation, all samples were aciddigested on a hot plate in concentrated $\mathrm{HNO}_{3}$ followed by aqua regia. The hair samples were pre-prepared for analysis by thorough sequential washing in order to eliminate exogenic uranium. The sample was first put in a syringe filled with detergent (Triton-X of $1 \%$ concentration) for 12 hours. The syringe with its content was thereafter put in an ultrasonic bath for $30 \mathrm{~min}$ with $55^{\circ} \mathrm{C}$ water as wave transport medium. The detergent was then cleared from the syringe through a filter to keep the hair inside the syringe. The sample was rinsed with two flushes of demineralized water and one of acetone and lastly it was dried.

For the $\mu$-XRF scans the hair shafts were mounted on a holder, see figure 7 , or placed on an adhesive carbon tape. 


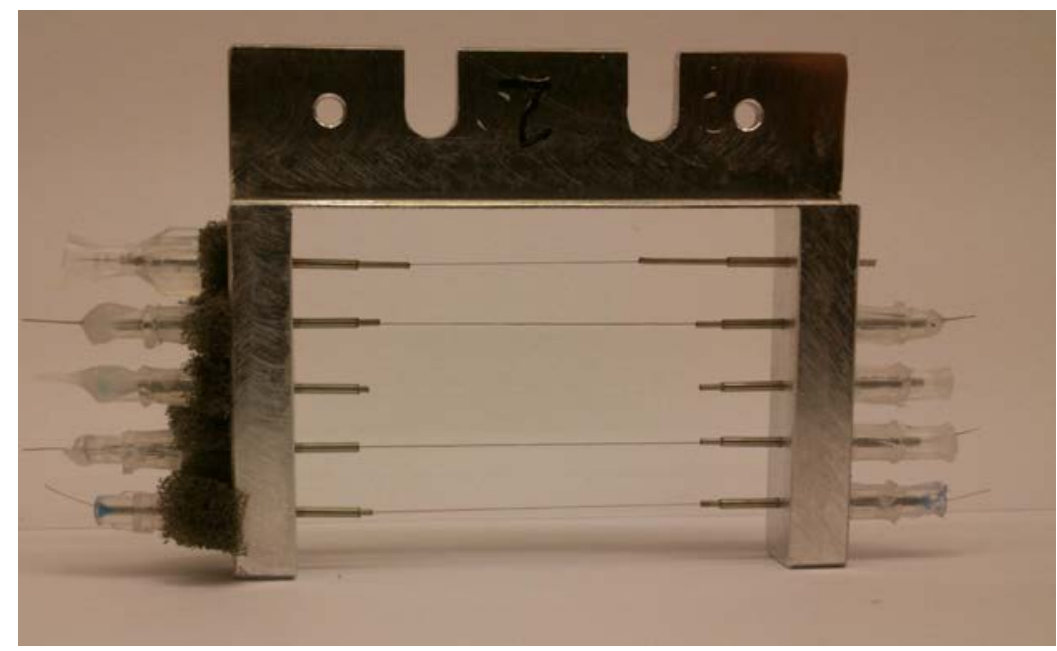

Figure 7. Hair shafts mounted on the holder used for $\mu$-XRF measurements.

\section{Radiochemical separation}

In order to detect ionizing radiation from materials with low concentration of radionuclides, one often needs to undertake processes to purify the radioactive elements. If not, radiation emitted from inside the material will be absorbed by the material itself and will not reach the detector. This is especially important when dealing with alpha- and beta- emitting radionuclides, which emit particles with short range. Radiochemical separation is also performed to remove radionuclides that emit radiation that disturbs the detection of that from the radionuclide of interest. There are different procedures available for uranium radiochemistry.

In the present work the separation of uranium was performed by liquid-liquid extraction using tributyl phosphate (TBP) (Holm 1984). TBP has a high affinity for actinide extraction. In $8 \mathrm{M} \mathrm{HNO}_{3}$, uranium has a high degree of complexing by TBP compared with most other metals. By repeated shaking of the sample dissolved in $8 \mathrm{M} \mathrm{HNO}_{3}$ with TBP, uranium is effectively transferred from the acid phase to the organic phase; $\mathrm{U}(\mathrm{VI})+\mathrm{HNO}_{3}+\mathrm{TBP} \rightarrow \mathrm{UO}_{2}\left(\mathrm{NO}_{3}\right)_{2}(\mathrm{TBP})_{2}$ (Morss et al. 2011). Competing actinides are thereafter removed from the TBP by diluting it with xylene and performing backextraction in $5 \mathrm{M} \mathrm{HCl}$. Finally uranium is back-extracted in demineralized water. The water phase is then evaporated to dryness after addition of $1 \mathrm{ml}$ of $0.3 \mathrm{M} \mathrm{Na}_{2} \mathrm{SO}_{4}$. The remaining salt is then dissolved in concentrated $\mathrm{H}_{2} \mathrm{SO}_{4}$. After adjustment of $\mathrm{pH}$ to 2.12.4, electrodeposition of uranium to a stainless steel disc is performed (Hallstadius 1984). 
The alpha measurements after the preparation process will not quantitatively measure the radionuclides, unless the chemical yield is known. That is accomplished by adding a yield determinant for the element to be measured prior to separation, in this case ${ }^{232} \mathrm{U}$.

\section{Alpha spectrometry}

By detecting alpha particles emitted from radioisotopes deposited on the surface of a disc, the alpha spectrometer provides a means to quantify the amount of the isotopes. As a solid state detector or semiconductor state detector it has much higher density than gas-filled detectors. Typically consisting of doped silicon with ionizing energy of about $3 \mathrm{eV}$, the detector has a high energy resolution due to the many charge carriers that are produced by each alpha particle. The high resolution is important to discriminate alpha particles from different radioisotopes. An alpha spectrum from a measurement on hair from a nuclear fuel factory worker is shown in figure 8 .

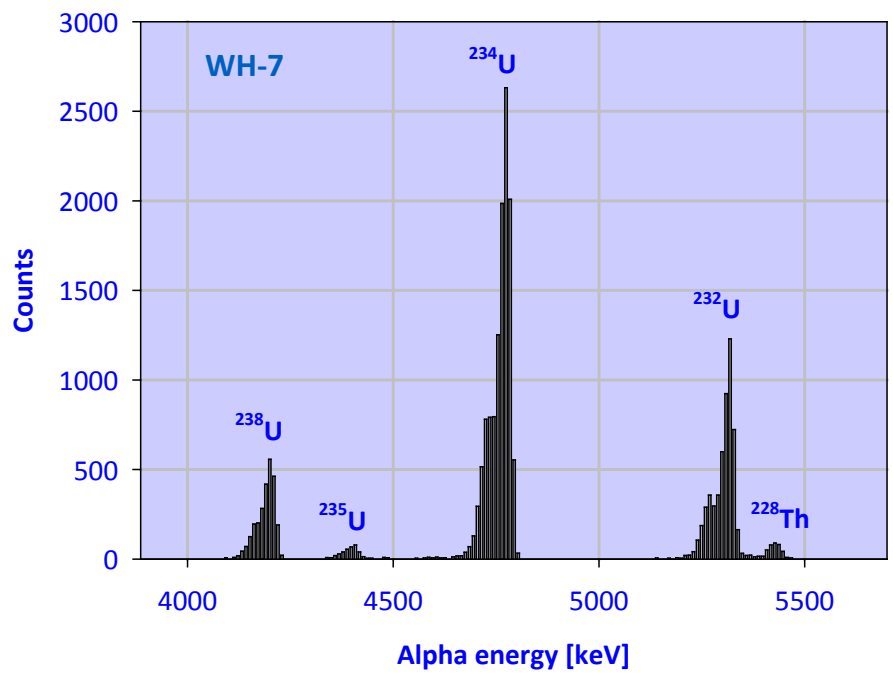

Figure 8. Alpha spectrum of uranium in hair sampled from a nuclear fuel factory worker.

$X R F$

$\mathrm{X}$-ray fluorescence is the emission of secondary photons (characteristic x-rays) from a material when it is exposed to ionizing radiation. Upon excitation, the atomic electrons (usually tightly bound from inner shells $\mathrm{K}$ and L) are dislodged. By detecting the photon energy spectrum of the secondary radiation emitted when outer electrons fill the vacancies, one can reveal the elemental compositions of various materials. That is possible because the energy of the secondary radiation is dependent on the electron binding en- 
ergies and those are unique for all elements. Thus, each element has its own specific characteristic x-ray emissions following transitions from outer to inner shells and XRF can be used to give information of almost all elements in the periodic system. In order to excite a specific electron the energy of the incoming photon need to be larger than the electron binding energy. Figure 9 shows simplified the shells of an atom and transitions between them.

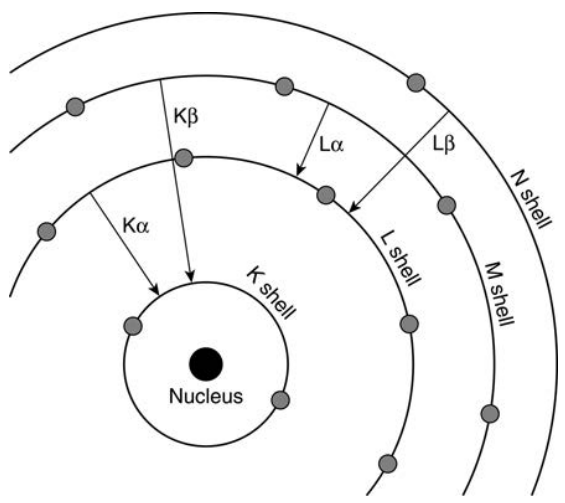

Figure 9. Four inner electron shells of an atom and transitions.

Synchrotron radiation is produced by charged particles in a cyclic particle accelerator. The particles are accelerated to relativistic velocities and constrained by bending magnets. As the charged particles are deflected by the magnets synchrotron light is produced. The light is monochromated to a specific wavelength (energy) and focused in accordance with the desired beamline properties. The photon energy can be chosen with high precision, which is advantageous for many applications. In SR-XRF, for example, an optimal photon energy which maximizes the excitation probability of a specific atomic shell and which minimizes scattered radiation is often chosen in order to detect atoms at very low concentration.

In the present work SR $\mu$-XRF measurements were carried out at the FLUO beamline of the ANKA synchrotron facility (Karlsruhe, Germany) (Simon et al. 2003). A monochromatic beam with photon energy $18.1 \pm 0.5 \mathrm{keV}$ and a photon flux of $\sim 10^{12} \mathrm{ph} \mathrm{s}^{-1}$ $\mathrm{mm}^{-2}$ was focused by a compound refractive lens (CRL) (Nazmov et al. 2004) to a beam size of a few micrometers. The photon energy was chosen to obtain ideal focus conditions of the lens and to optimize the conditions for excitation of uranium $\mathrm{L}_{3}$ electrons.

The focus dimensions were measured by knife edge scanning of a $5 \mu \mathrm{m}$ thin $\mathrm{Ni} / \mathrm{Fe}$ structure (IRMM 301 standard). The beam size was measured to $3.0( \pm 0.1) \times 6.8( \pm 0.1)$ $\mu \mathrm{m}^{2}$. The resulting micro beam had an intensity of about $4 \cdot 10^{9} \mathrm{ph} \mathrm{s}^{-1}$ in the focal spot. The uranium intensity was determined from the corrected (detector dead-time and beam intensity) $\mathrm{U}_{\alpha}$ X-ray line of $13.6 \mathrm{keV}$. 


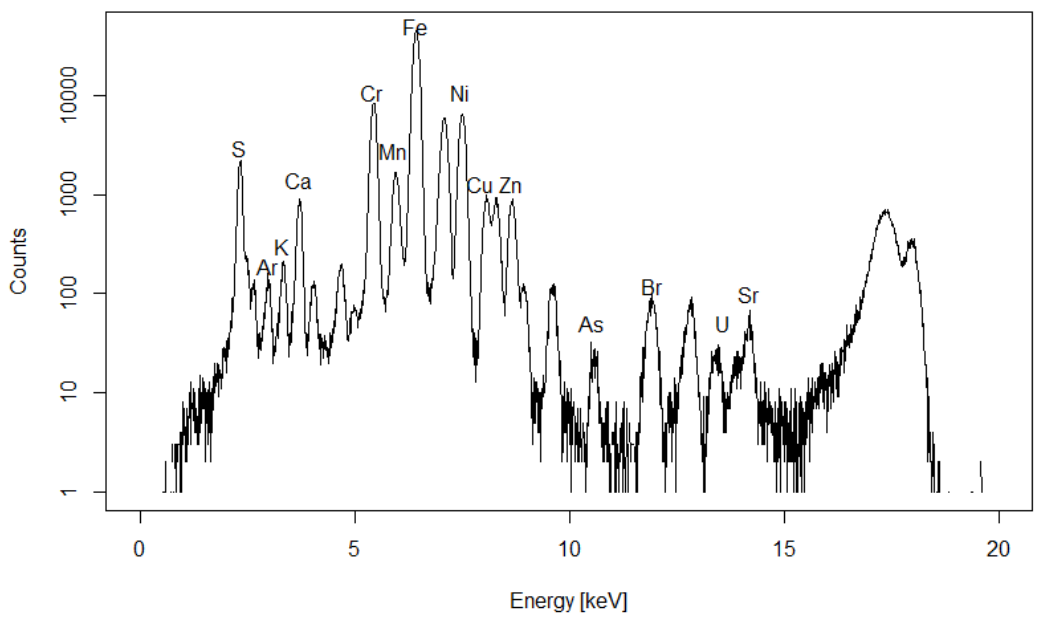

Figure 10. SR $\mu$-XRF spectrum of a single volume element of an unwashed hair shaft from a user of water from a drilled bedrock well. 



\section{Quality assurance}

The radiometric analyses of the samples were evaluated using standardized procedures developed at Radiation Physics Department, Linköping. The laboratory is part of a national network of laboratories for operational preparedness and research in the field of radiological and nuclear accidents. In this setting the laboratory annually participates in national and/or international intercomparisons, such as those organized by the IAEA, in order to assure the analytical quality. Some intercomparisons involve radiochemical analysis of uranium in various matrices, like fresh water, marine water, sediments, biota, and have yielded satisfactory results for the laboratory.

The alpha spectra were read out by manual setting of regions of interest (ROI) for each alpha peak in the spectra. It is common practice to do it manually, since the peaks sometimes are slightly broadened due to variable electro deposition quality and occasionally due to high uranium levels. Background was subtracted from each spectrum using background count rates obtained for each detector.

Prior to chemical separation of the samples, a yield determinant ${ }^{232} \mathrm{U}$ was added to each sample. The yield determinant has a certified activity concentration, traceable to National Institute of Standards and Technology (NIST). By adding a known activity of ${ }^{232} \mathrm{U}$ to the sample prior to sample treatment, and using the fact that the uranium isotopes will show identical chemical behavior in the chemical processing (aciddigestion followed by separation and electrodeposition), the chemical recovery will be identical for all the isotopes. Thus, the activity of each sample uranium isotope is easily determined from the ratio of the alpha peak areas of the uranium isotope and the yield determinant. For the hair samples, the yield determinant was added after the washing procedure.

Analyses of three blank urine samples were also performed. The preparations of these were performed identically to regular urine sample preparations. The obtained mean activity of the blanks was $63 \pm 16 \mu \mathrm{Bq}$, which was then subtracted from the urine sam- 
ple concentrations. The uranium in the blank samples is thought to derive from the chemicals (analytical grade) used in the sample treatment, in particular the acids since fairly large acid amounts were used for urine sample treatment.

The uncertainty, $d N$, in the number of detections (counts), $N$, was given by the standard deviation of the Poisson distribution $d N=\sqrt{N}$. Propagation of uncertainty was used for determining uncertainties of derived quantities such as the activity concentration. In order to assess the variability in the hair and urine sample preparations, five hair subsamples and six urine sub-samples from the same samples were washed and analyzed. Relative inter-sample standard deviations $(1 \sigma)$ for the ${ }^{234} U$ activity were found to be $18 \%$ and $4 \%$ for hair and urine respectively and for the ${ }^{238} \mathrm{U}$ activity it was $12 \%$ and $8 \%$ for hair and urine. The larger values for hair could be due to the variable washing efficiency. The hair sub-samples may also have had larger activity variation due to the difficulty of mixing the sample before picking sub-samples.

Apart from the statistical uncertainty, there is also an uncertainty of systematical character due to the uncertainty of the ${ }^{232} \mathrm{U}$ tracer $(2.2 \%)$ and the balance used to weigh the samples. This uncertainty is small in comparison to the statistical uncertainties and is not as important, since the conducted measurements mainly are for comparing data with the same systematic uncertainties.

\section{SSM functional exercise}

The use of chewing gum as a dosimeter was tested as part of a functional exercise conducted by the Swedish Radiation Safety Authority (SSM) within the program for Emergency preparedness and response. Four chewing gums irradiated with ${ }^{60} \mathrm{Co}$ to two different doses between 0-10 Gy were sent to the Radiation Physics laboratory in Linköping.

The method presented in paper I was used with some modifications. The most notable are the number of spectra acquired and their duration. In this test 13 background, 9 calibration and 12 blind sample spectra were acquired compared to 200 background, 100 calibration and 80 blind sample spectra in paper I. However, the duration time of the spectrum acquisition was in this test increased from $400 \mathrm{~s}$ to $1000 \mathrm{~s}$. The measurements were carried out during one day, 3 days after irradiation compared to 4-6 days after irradiation in Paper I.

The EPR measurements and analysis resulted in the doses $1.6 \pm 0.8 \mathrm{~Gy}$ and $3.1 \pm 0.9 \mathrm{~Gy}$ (1 SD). The doses given at SSM were later announced to $0.78 \mathrm{~Gy}$ and $2.4 \mathrm{~Gy}$ with uncertainty 5-10\% (2 SD).

The EPR retrospective dosimetry methods performed at the laboratory at Radiation Physics Dept, Linköping has recently been validated in two European intercomparison 
studies: One on smart phone touch screen glass (Fattibene et al. 2014) and one on tooth enamel (Fattibene et al. 2011). The uncertainty analysis of the EPR measurements conducted in this thesis is described in the appendix of paper I. 



\section{Results}

\section{EPR}

\section{Summary Paper I}

The purpose of this investigation was to study the radiation-induced EPR signal in sweeteners xylitol and sorbitol for use in retrospective dosimetry. For both sweeteners and chewing gum, the signal changed in an interval of 1-84 days after irradiation with minimal changes 4-8 days after irradiation. A dependence on storage conditions was noticed and the exposure of the samples to light and humidity was therefore minimized. Both the xylitol and sorbitol signals showed linearity with dose in the measured dose interval, 0-20 Gy. The dose response measurements for the chewing gum resulted in a decision threshold of $0.38 \mathrm{~Gy}$ and a detection limit of $0.78 \mathrm{~Gy}$. A blind test illustrated the possibility of using chewing gums as a retrospective dosimeter with an uncertainty in the dose determination of $0.17 \mathrm{~Gy}(1 \mathrm{SD})$.

\section{$\underline{\text { Additional results }}$}

\section{EPR on sucrose}

Sucrose is a well known EPR dosimeter material which has also been used after real accidents (Nakajima 1994, Fattibene et al. 1996, Hutt et al. 1996, Karakirova et al. 2008). Similar to sorbitol, unlike xylitol, displayed in paper I, measurements on sucrose showed just small signal dependence with time after irradiation. No major peak intensity changes were found for a sample irradiated to 20 Gy measured with modulation amplitude $0.2 \mathrm{mT}$, figure 11 . 


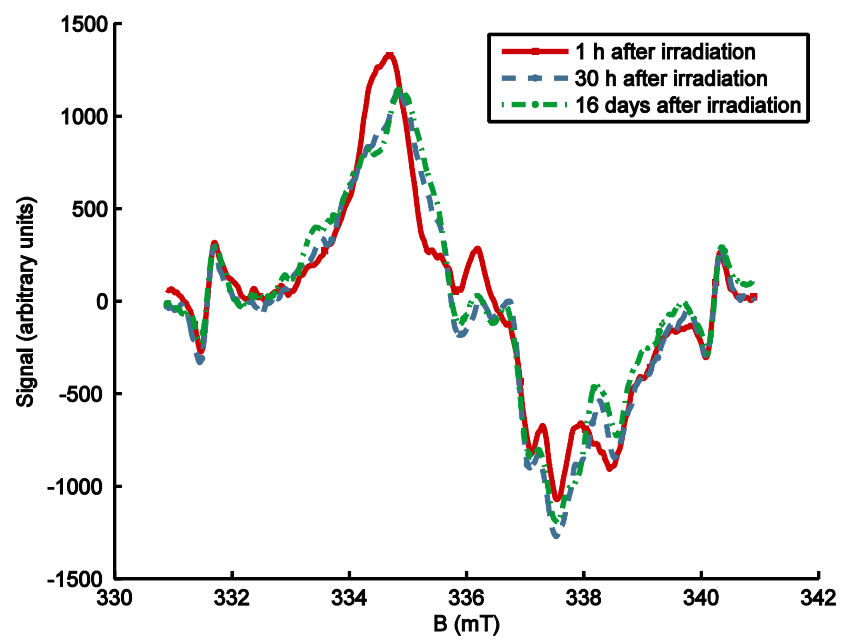

Figure 11. Three EPR spectra of sucrose irradiated to 20 Gy displaying the signal variation with time after irradiation.

\section{$\underline{\text { Precision in dose determinations }}$}

The V6 (Cadbury Sweden AB) dose response measurement described in paper (I) included measurements of 5 tablets irradiated to $4.0 \mathrm{~Gy}, 10$ background tablets and 4 blind test tablets. Each tablet was measured 20 times. The mean and standard deviation from these measurements are plotted in figure 12. The mean values of the background and irradiated tablets were used for the calibration curve.

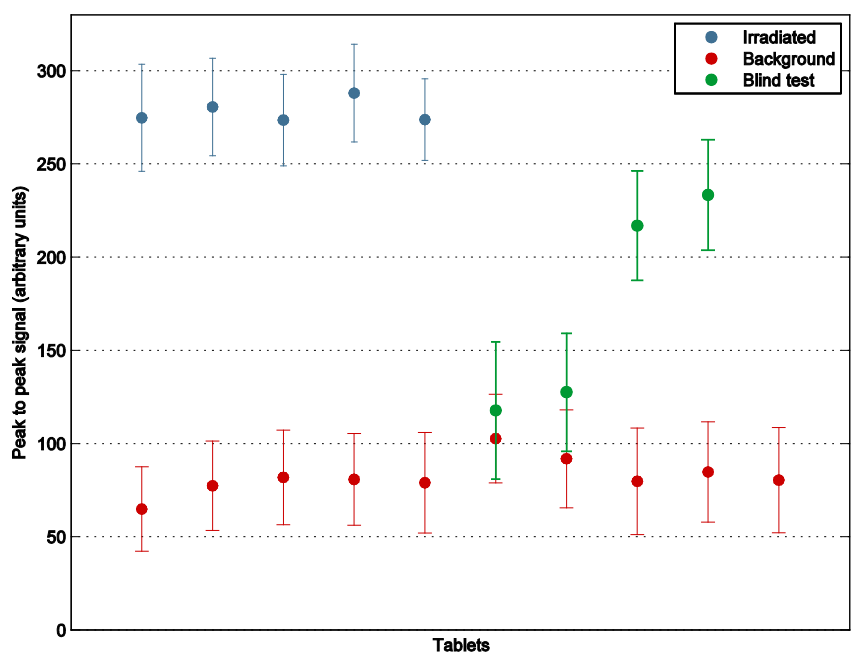

Figure 12. Background, irradiated and blind test tablets of V6 chewing gum. 
The 10 background tablets as well as the 5 irradiated tablets were measured in rounds. After the first measurement of all background tablets were done, the second round of measurements started and so forth. In figure 13, the mean value and standard deviation of the tablets are shown for each round of measurement. The irradiated tablets were measured over 3 days from 4-6 days after irradiation. The signal dependence with time after irradiation was found to be insignificant during this interval.

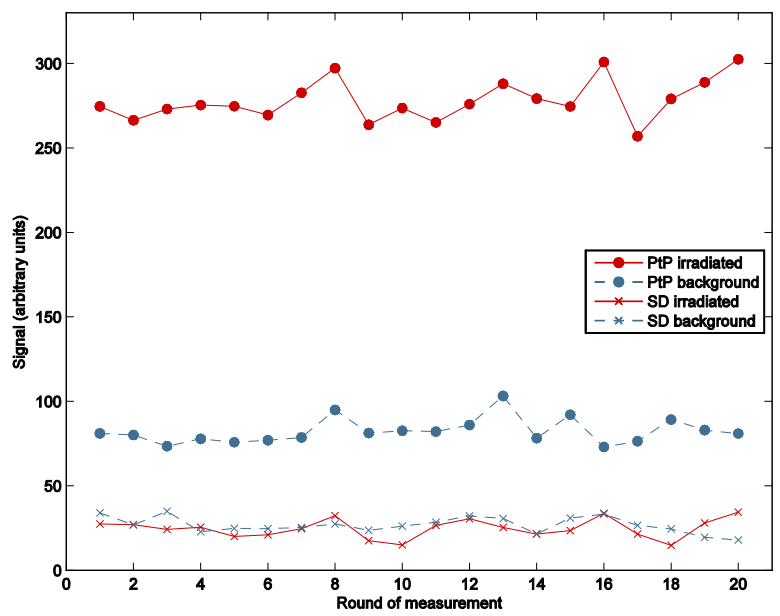

Figure 13. Mean peak to peak (PtP) values and standard deviations (SD) of the 10 background and 5 irradiated chewing gum tablets for all 20 measurement rounds.

\section{Uranium in hair}

\section{Summary Paper II}

Hair is evaluated and compared with urine as biomonitor for human intake of uranium. Concentrations of ${ }^{234} \mathrm{U}$ and ${ }^{238} \mathrm{U}$ and their activity ratios are measured in hair, urine and drinking water of 24 drilled bedrock well water users in Östergötland, Sweden. The samples are measured with $\alpha$-spectrometry after radiochemical preparation using liquidliquid separation with TBP.

The results show that there is a stronger correlation between the uranium concentrations in the drinking water of each subject and the hair of the subject $\left(\mathrm{r}^{2}=0.50\right)$ than with the urine $\left(r^{2}=0.21\right)$. There is also a stronger correlation between the ${ }^{234} U /{ }^{238} U$ activity ratios of water and hair $\left(r^{2}=0.91\right)$ than between water and urine $\left(r^{2}=0.56\right)$. These results imply that hair may serve as a robust indicator of chronic uranium intake. One obvious advantage over sampling urine is that hair samples reflect a much longer excretion period; weeks to months compared to days. 
The absorbed fraction of uranium, the $f$ value, is calculated as the ratio between the excreted amount of uranium in urine and hair per day and the daily drinking water intake of uranium. The $f$ values range from 0.002 to 0.10 with a median of 0.023 .

\section{Summary Paper III}

Scalp hair is evaluated and compared with urine as a potential biomonitor following inhalation intake of uranium. The samples were collected among eight workers at a nuclear fuel fabrication factory and the sample concentrations of ${ }^{234} U$ and ${ }^{238} U$ were analyzed by $\alpha$-spectrometry after radiochemical separation using a TBP-based liquid-liquid separation method. Personal air samplers (PAS) filters were also analyzed for estimation of inhaled uranium activity.

The results show that there is a large day-to-day variation $\left(7-70 \mathrm{~Bq} \mathrm{d^{-1 }}\right.$ ) of the inhaled

${ }^{234} \mathrm{U}$ activity over a 6 week period. A large variation is also seen for the ${ }^{234} \mathrm{U}$ activity concentration among 12 urine samples collected over a 12 week period; (2-50 mBq kg$\left.{ }^{1}\right)$. Four hair samples from the same subject and period showed less variation (100-240 $\mathrm{mBq} \mathrm{g}^{-1}$ ) as they reflect the average excretion over a longer period than the periodic urine samples.

The total inhalation intake and excretion in urine and hair was obtained for two study subjects over a 6 week period. The uranium inhalation to urine and hair factors $f_{\text {inh, }}$ and $\mathrm{f}_{\text {inh,h }}$ were 0.0014 and 0.0002 respectively, given by calculations based on the measured PAS, urine and hair data. It has been demonstrated that scalp hair could be a valuable complement to urine as biomonitor of uranium intake.

\section{Summary Paper IV}

In the present study the distribution of uranium in single human hair shafts has been evaluated using two synchrotron radiation based micro X-ray fluorescence techniques; SR $\mu$-XRF and confocal $\mu$-XRF. The hair shafts originated from persons that have been exposed to elevated uranium concentrations. Two different groups have been studied, i) workers at a nuclear fuel fabrication factory, exposed mainly by inhalation and ii) owners of drilled bedrock wells exposed by ingestion. The measurements were carried out on the FLUO beamline at the synchrotron radiation facility ANKA. The experiment was optimized to detect $U$ with a beam size of $6.8 \mu \mathrm{m} \times 3 \mu \mathrm{m}$ beam focus allowing detection down to ppb levels of $U$ in $10 \mathrm{~s}$ ( $\mu$-XRF setup) and $70 \mathrm{~s}$ (confocal $\mu$-XRF setup) measurements. It was found that the uranium was present in a $10-15 \mu \mathrm{m}$ peripheral layer of the hair shafts. Furthermore, scanning of unwashed hair shafts from the workers revealed sites of very high uranium signal identified as particles containing uranium. Particles, believed to contain uranium, were also seen in complementary scanning electron microscope (SEM) images. However, the particles were not visible in washed hair shafts, and were therefore recognized as removable. 
These findings can further increase the understanding of uranium excretion in hair and its potential use as a biomonitor.

\section{$\underline{\text { Additional results }}$}

\section{Different hair shaft wash methods}

Different hair shaft wash methods were tested prior to the start of experiments involving washed hair shafts in papers (II-IV). 19 sub-samples with masses 0.2 g were picked from a large hair sample about $6 \mathrm{~g}$ from a worker at Westinghouse nuclear fuel fabrication factory. 8 different washing schemes were tested. These were modifications of a method used by (Akamine et al. 2007) in which the hair samples are washed in 2\% Triton-X (a non-ionic detergent) demineralized water and acetone, in that order. The washing in each substance was performed in an ultrasonic bath at $55^{\circ} \mathrm{C}$ for 10 minutes. Each scheme was applied on two samples and three samples were left unwashed. Analyses were performed using alpha spectrometry following radiochemical separation. The results are shown in figure 14.

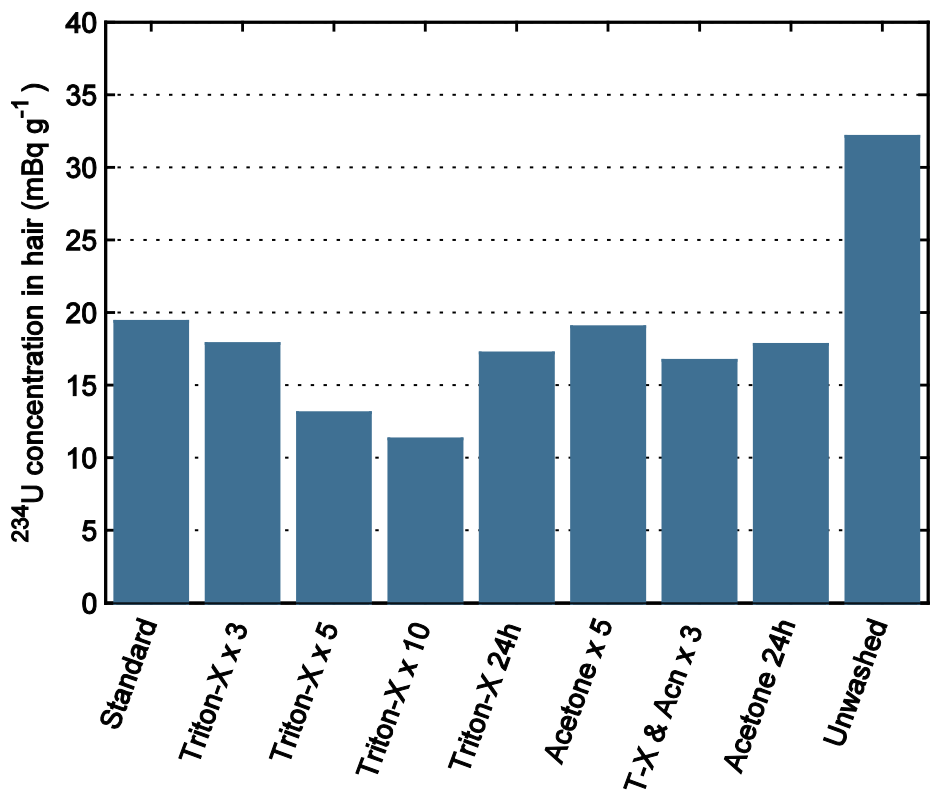

Figure 14. Resulting mean ${ }^{234} \mathrm{U}$ concentration after different washing schemes. 'Standard' refers to 10 minute ultrasonic cleaning in Triton-X, demineralized water and acetone respectively. The other methods had either $n$ times cleaning in a substance beyond the cleaning in the other two or were complemented with a $24 \mathrm{~h}$ stay in the stated substance. 


\section{Confocal 2D on hair shaft cross section}

In addition to the sample of an unwashed hair shaft of a nuclear fuel fabrication factory worker presented in paper (IV), a confocal $\mu$-XRF measurement was also performed on a washed hair shaft from the same sample. The two 2D maps display approximately a quarter of the shaft cross sections and are shown in figure 15 and 16. The images differ in a number of ways. First of all, the hair in figure 15 is thinner and a larger part of the hair is covered by the field of view. This explains the curvier uranium distribution than is seen in figure 16. It is also evidently higher uranium signals in the unwashed workers hair. It seems that the uranium in the washed shaft is somewhat smeared out. However, the resolution is at its worst in the down-left to upper-right direction due to the X-ray optics and the experimental set-up. Each pixel corresponds to a measurement over 18.4 $\mu \mathrm{m}$ in this dimension and that is a probable explanation for the 'smearing' not being seen in the opposite down-right to upper-left direction.

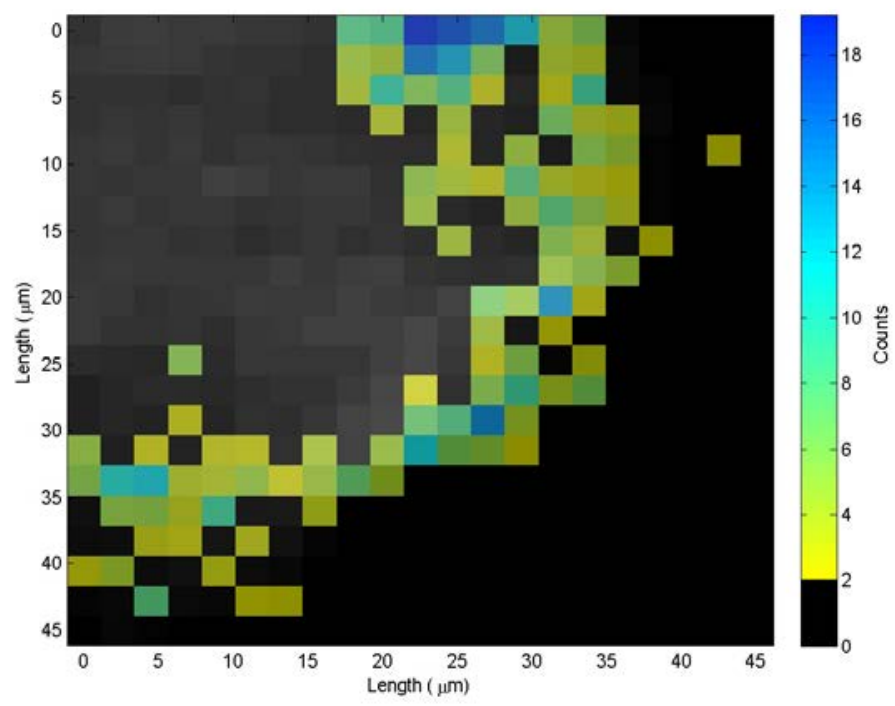

Figure 15. Bitmap representation of a quarter of the full cross section of a hair shaft obtained with confocal $\mu$-XRF. Upper left corner shows the shaft centre. The uranium $L_{\alpha}$ intensity map (yellow/blue scale) is superimposed on the zinc $\mathrm{K}_{\alpha}$ map (gray scale) with white and blue indicating higher signals. The hair shaft is washed and was sampled from a worker at a nuclear fuel fabrication plant. 


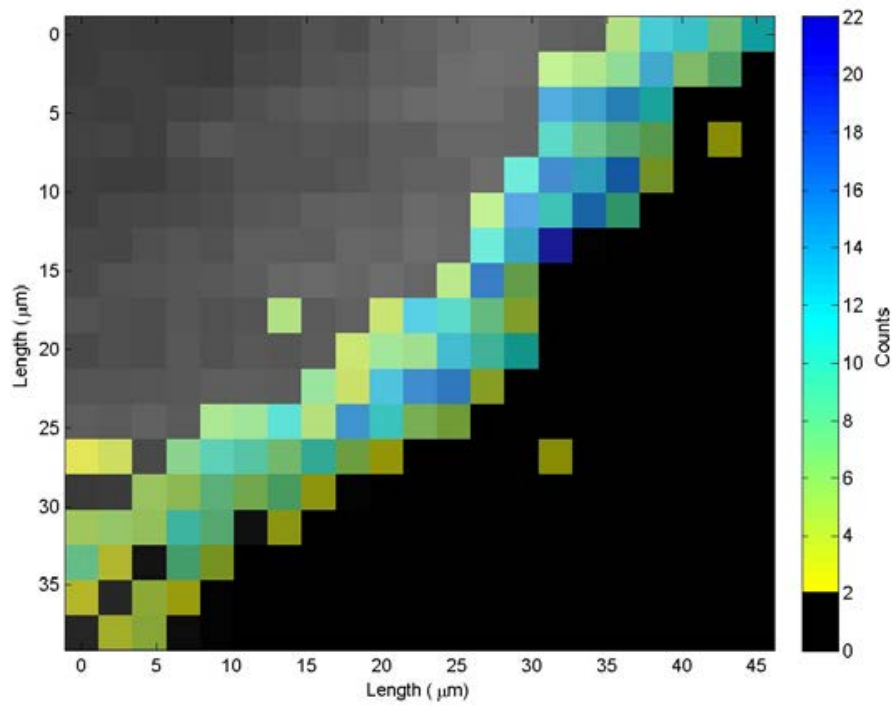

Figure 16. Bitmap representation of a quarter of the full cross section of a hair shaft obtained with confocal $\mu$-XRF. Upper left corner shows the shaft centre. The uranium $\mathrm{L}_{\alpha}$ intensity map (yellow/blue scale) is superimposed on the zinc $\mathrm{K}_{\alpha}$ map (gray scale) with white and blue indicating higher signals. The hair shaft is unwashed and was sampled from a worker at a nuclear fuel fabrication plant.

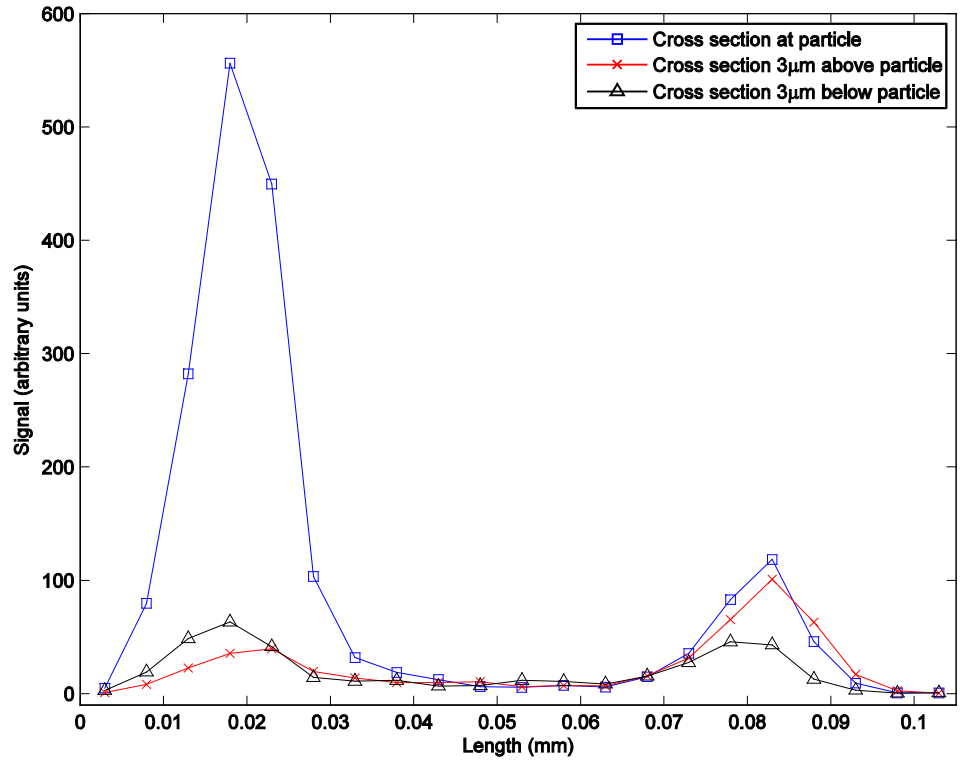

Figure 17. Uranium signal from cross sectional 1D $\mu$-XRF scans in the vicinity of a particle in an unwashed hair from a nuclear fuel fabrication factory worker. 


\section{$\mu$-XRF at particle site}

The uranium particles found in the longitudinal $\mu$-XRF scans of the hair, described in paper (IV) were further studied with latitudinal scans. Figure 17 shows 3 such scans separated by $3 \mu \mathrm{m}$ at a particle site. With the resolution of $3 \mu \mathrm{m}$ in the longitudinal (z) direction, these scans are covering the whole hair section without overlap. Assuming that only the middle scan shows a signal from the particle it can be concluded that the particle is $<3 \mu \mathrm{m}$ in the $z$ direction. 


\section{Discussion}

The characterization of xylitol and sorbitol as retrospective dosimetry materials and the proven use of a chewing gum type show that sweeteners and products containing sweeteners can be used as retrospective dosimeters following a radiation accident. Other chewing gum types, as well as certain kinds of candies, are likely also suitable given that the presence of sweetening is high and or easy to separate (without affecting the magnetic properties of it) from the rest of the product. Chewing gums with sweetened coating around the gum base is probable to be the easiest to collect high amounts of relatively pure sweetening from.

The detection limit of chewing gum, $0.78 \mathrm{~Gy}$, is fairly low compared to other materials analyzed with EPR for retrospective dosimetry. In a review study by Trompier et al. (2009) only sugar had a lower detection limit; 0.2 Gy. Glass, nails, and in-vivo toothenamel all had a detection limit of about 2 Gy. However, a detection limit of 0.2 Gy has been reported for both tooth enamel biopsies and extracted teeth (Ainsbury et al. 2011, Fattibene et al. 2011). Chewing gum also holds other desirable qualities such as linearity with dose and ubiquity. Even if it is not carried by a majority of people, a presence among the public of $10-30 \%$ may not be unrealistic. The time-dependence of the EPR signal in xylitol is a limitation. But as is shown in figure 13, there is no signal difference between 4 and 6 days after irradiation, which is a realistic time frame for dose assessments after an accident or a dirty bomb scenario.

The excretion of uranium into hair is compared with excretion of uranium in urine after two different intake scenarios; ingestion of water with elevated uranium concentrations and inhalation of uranium particles at a nuclear fuel fabrication factory. It is tangible that the uranium concentration in hair better reflects the chronic intake after both ingestion and inhalation than urine. Urine sampling, which is the most established way to derive uranium body burden and intake, is suitable for assessments of the short term excretion of uranium, i.e. the last 3 days, but could only be considered as random sam- 
pling when acquired every $3^{\text {rd }}$ month after chronic intake. The excretion rates of uranium in hair following ingestion intake is fairly well known (Karpas 2001, Mohagheghi et al. 2005, Karpas et al. 2005a, Muikku et al. 2009). The results presented in paper (II) and (III) further acknowledge hair as an excretion pathway and possible biomonitor. The biokinetic model presented in ICRP 69 (1995) needs a revision to include hair as an compartment, as is proposed by Li et al. (2009). This will allow changes in internal dose calculation softwares such as IMBA (Birchall et al. 2003), which are widely used for deriving intakes and doses based on excreted activity. However, further studies are needed to better control the uncertainties involved. The excreted uranium concentration dependence with hair qualities such as color, thickness, growth rate and treatments should for example be addressed. Variation based on preparation of the hair prior to analysis, i.e. the washing procedure, also needs to be investigated further, see below. To our knowledge, there has been no previous studies on the uranium excretion in hair following inhalation intake. Hence, the dynamics behind intake and subsequent excretion are, to a large extent, unknown. In paper (III) the inhaled uranium to hair factor $f_{\text {inh }, h}$ was found to be 0.0002 which is about one order of magnitude lower than the determined ingested uranium to hair factor $f_{\text {ing,h }}$ of about 0.003 . The inhaled uranium to urine $f_{\text {inh }, u}$ factor of 0.0014 differs to the ingested uranium to urine factor $f_{\text {ing, } u}$ of 0.02 with an equal factor. The reason for the lower fractions for inhaled intake may be attributed to the large fraction of inhaled uranium that is rapidly either exhaled or cleared via the GI-tract.

The $\mu$-XRF measurements displayed in paper (IV) revealed where the uranium is located in single hair shafts. Unwashed hair shafts from the workers at the nuclear fuel factory displayed particles containing uranium, > 20 particles per mm. These were removed by the washing procedure. That exogenous uranium is removed by washing is also evident from the washing method study, see figure 14. Even though the $\mu$-XRF scans of washed hair shafts show no particularly sharp peaks like the unwashed shafts, it cannot be concluded that all exogenous uranium is removed by washing. Further studies are needed to thoroughly examine to which extent the exogenous uranium is removed and to see whether endogenous uranium is removed. That the uranium is found to be located peripherally in the shafts may increase the risk of removing endogenous uranium. However, there should be a balance in which only very small amounts of exogenous uranium are left on the shaft and only small amounts of endogenous uranium are removed during washing. 


\section{Conclusion}

In this thesis, new discoveries and further information on potential retrospective dosimeters are presented. The EPR spectra of irradiated xylitol and sorbitol were characterized. Spectral dependence with time after irradiation was found, although it was minimal in the time period of 4-8 days. A method for dose determinations of irradiated chewing gum was tested successfully in a blind test with uncertainties of 0.3 Gy (2 SD). Chewing gum containing xylitol or sorbitol could be used for retrospective dose determination with a detection limit of $0.8 \mathrm{~Gy}$, which is sufficient for making determinations within a week following radiation incidents.

Hair was shown to be a satisfactory alternative to urine for monitoring chronic uranium intake by ingestion and inhalation. The concentration of uranium and the ${ }^{234} U /{ }^{238} U$ isotope ratio are better correlated between intake and excretion in hair than in urine after chronic ingestion and inhalation. Both the fraction of inhaled uranium excreted in the urine and the fraction excreted in hair is an order of magnitude smaller than the excreted fractions from ingestion. The uranium concentration is about 10000 times higher in hair than in urine. Hair is easy to collect. $0.1 \mathrm{~g}$ of hair was sufficient to make accurate quantitative uranium analyses.

It is possible to detect uranium at the fg level and visualize its distribution in single hair shafts by using SR $\mu$-XRF and confocal $\mu$-XRF. The resolution is of the order of micrometers, which allows for detailed longitudinal and latitudinal scanning of the hair shafts. The uranium is unlike other studied elements located in the periphery of the shaft in what seems to be a layer of about 10-15 $\mu$ m thickness. In the unwashed scans of the factory workers' hair, uranium particles of $\mu \mathrm{m}$ size were found. No particles were detected in washed hairs. However, the effects of the applied washing procedure should be studied further. Chronology scans should be performed with alternative methods preferably using a larger sized beam that covers the width of the shaft. 



\section{Future developments}

From the present thesis several areas can be identified for further investigations.

\section{EPR on chewing gum}

The method of using chewing gum as a dosimeter after an unexpected irradiation event that is presented in paper I can be improved by identifying the chemical form of the radicals formed upon exposure. By performing single crystal EPR measurements of the sweeteners contained in the chewing gum, the molecular structure can be determined. This will allow for simulations of the EPR spectra, which in turn can aid the radical concentration determination.

Other chewing gums than the V6 used in paper I and candies containing xylitol, sorbitol or other sweetening agents are also of interest to study for the use as retrospective dosimeters. To establish a library of the characteristics, e.g. dose response, signal dependence with time after irradiation, and optimal storage conditions, for many sweetening agents and products containing them would be highly valuable once the dose determinations are called for. It would be optimal to have calibration curves of different sweeteners and chewing gum available before the irradiation event occurs.

\section{Other hair analyzing techniques}

Apart from alpha spectrometry following radiochemical separation and the $\mu$-XRF studies used in papers II-IV other hair analyzing techniques should be explored. Quantitative techniques such as ICP-MS, AMS, TIMS and LASER-excitation as well as imaging techniques such as SEM, TEM, should be evaluated and compared for uranium in hair analyses. 


\section{Controlled uranium intake}

A controlled intake study, in which test subjects eat or drink a predetermined activity of uranium and are followed up with measurements on excreted U activity in hair, blood, urine and perhaps feces, could answer several questions. The test subjects would be chosen from persons not having any elevated levels of uranium in their household water nor working in the nuclear industry. By using uranium with a specific isotopic signature $\left({ }^{235} U /{ }^{238} \mathrm{U}\right.$ and $\left.{ }^{234} \mathrm{U} /{ }^{238} \mathrm{U}\right)$, any other intake of natural uranium, e.g. from food, can be assessed. Described below are four parts of this controlled intake study.

\section{$\underline{\text { Temporal excretion }}$}

By periodic sampling of hair, blood, urine and feces after a single intake, the excretion dynamics after intake is obtained for these sample types. The position of the uranium in the hair shafts will correspond to the elapsed time since intake. The measured uranium activity in hair and urine should be measured with respect to the uranium activity in blood in order to obtain the transfer rates between blood and hair and between blood and urine.

\section{Fractional excretion}

The fractional activity excreted in hair could be determined with higher precision than in paper II as the activity intake is well-known and as the risk of contaminating the hair is negligible.

\section{Chronology}

As paper IV showed, chronological measurements, i.e. time-resolved uranium excretion in hair, should be made with a broader beam than at the FLUO beamline $\mu$-XRF. That is possible at the Synchrotron Laboratory for environmental studies (SUL-X) beamline at ANKA, Karlsruhe. It should ideally cover the shaft width in order to detect all uranium at each longitudinal shaft segment. With a well controlled varying activity intake over a period (e.g. a month), the ability to reproduce the intake history by the XRF scans is studied.

\section{Endogenous removal}

With no external contamination, all uranium that is removed is endogenous. Paper IV showed that the uranium is located peripherally. The fraction of removed endogenous uranium by the washing method therefore needs to be assessed in order to make sure that the washing does not distort the uranium signal. 


\section{Hair analysis development}

\section{Washing method}

The washing of the hair needs to be further studied. The method employed in papers IIIV need to be analyzed in order to evaluate the effect and efficiency of each step. Particle removal, possible endogenous uranium removal and/or relocation need to be addressed.

\section{Other alpha-emitting radionuclides}

Apart from uranium other long-lived alpha-emitting radionuclides, e.g. ${ }^{210} \mathrm{Po}$, ${ }^{226} \mathrm{Ra}$, Thand Pu-isotopes are possibly also excreted in hair. ${ }^{210} \mathrm{Po}$ and ${ }^{226} \mathrm{Ra}$ are often abundant in drilled bedrock well water and may give larger contributions to dose than ${ }^{234} \mathrm{U}$ and ${ }^{238} \mathrm{U}$. As alpha emitters they are detected through alpha spectrometry following radiochemical separation.

\section{Hair properties}

\section{Synthesis}

The potential of using hair as a bioindicator for uranium is governed by mechanisms behind the hair synthesis. In order to use the full potential, these mechanisms and their effect on uranium must be understood. By collaboration with experts on biological and chemical analyses of hair, studies of the uranium excretion may be designed which can reveal the unknown processes behind uranium excretion into hair.

\section{Hair type dependence}

The uranium excretion dependence on hair type needs to be investigated. The influence of color, thickness, growth rate and hair treatments may significantly influence the excreted uranium. However, a study on the influence of these parameters requires a fairly large study population in order to draw conclusions with statistical certainty.

\section{Length dependence}

Hair is worn out with time and endogenous loss of uranium is expected and increasing with hair lengths. This uranium loss per hair length should be investigated in order to be able to accurately correct for it.

\section{Internal dosimetry}

In order to make proper dose estimates following inhalation of uranium aerosols there are several parameters that needs to be investigated apart from knowledge of the uranium activity intake; the uranium aerosol activity size distribution, the morphology of the uranium particles, the chemical form of the inhaled uranium particles and thus the solu- 
bility in the lung fluids. Some of these parameters have been addressed in the field of nuclear fuel fabrication, but further studies are definitely motivated, especially since size distributions and morphology are site specific.

\section{Body burden}

The body burden is important to assess for individuals that have been chronically exposed to uranium. Workers in nuclear fuel factories inhale aerosols of uranium oxide that may reside in the lung tissue for months to years and uranium transferred to blood will partly be retained in the bone tissue, with retention times of years. Studying the dynamics of the body burden could be achieved by analyzing uranium in hair and urine when the chronic exposure has stopped. By following retired workers at a nuclear fuel factory for several years, the body burden can be derived from the uranium excretion rate in the excreta. Another way to determine the body burden would be to analyze bone biopsies of deceased. 


\section{Acknowledgements}

The writing of this thesis was made possible thanks to many wonderful people. Without your contributions and support, be it practical, theoretical or mental, I would have never been able to complete this $\mathrm{PhD}$.

I could not have asked for better supervisors.

Håkan B.L. Pettersson is a very generous and knowledgeable mentor to which I owe my greatest thanks. He is formidable person and a great companion.

Eva Lund took on a lot of responsibility for my development during the $\mathrm{PhD}$ which $\mathrm{I}$ am very thankful for. I have the greatest respect for her.

Håkan Gustafsson was especially valuable in the first two years of this PhD. Always well prepared, careful, focused, ambitious and professional, he was a role model.

Mats Eriksson introduced me to XRF and ANKA and has taken very good care of me both on the trips to Karlsruhe and on SSM. I am grateful for his encouraging support.

Apart from the supervisors, others have also participated in the progress of this thesis. Marie Carlsson has been wonderful in helping out with all kinds of things related to the chemistry lab. I owe thanks to Hans Mellander, Josefin Holmstedt, Ulrika Thorsen and Edvin Hansson at Westinghouse Sweden AB for providing knowledge, samples and data. Sara Olsson, Peter Larsson, Alexandru Dasu and the oncology nurses at Radiation Treatment are acknowledged for the help with irradiation of chewing gums. I especially want to thank Bengt Frost for constructing irradiation phantoms and for lending his high skill micro precision inventive hair shaft holder construction ability. My friend and colleague during the well project Ylva Ekholm is thanked for the organizing of the well water user sample collection. My longtime friend and graphic designer Nora Ahlenius is 
thanked for the design of a poster and this thesis cover. Lena Lundman is thanked for the support with ICP-MS trials.

My friends and colleagues Emelie Adolfsson, Mattias Karlsson, Oscar Ardenfors and Laura Antonovic are thanked for their support. Sharing offices, we have talked, laughed, sometimes wept and worked hard as we struggled with radiation and research.

I would also like to thank all other great colleagues at Radiofysik. You know who you are. The atmosphere in the fika-room of radiofysik is consistently very welcoming and friendly.

I would also like to thank the doctoral student organization at the faculty, DOMFIL, my friends in Linköping and elsewhere, SSM for their hospitality, ice hockey team Pittsburgh Penguins for their inspiring and entertaining and peace organization CISV.

My family Annelie, Bertil, Erik, Carl and Nils are thanked for their support. My girlfriend Sanna is thanked for proofreading and for her love and support. Thanks also to our newborn son Volmar for being adorable. 


\section{References}

Ahlers FJ, Schneider CCJ. Alanine esr dosimetry: An assessment of peak-to-peak evaluation. Radiat Prot Dosim 37: 117-122; 1991.

Ainsbury EA, Bakhanova E, Barquinero JF, Brai M, Chumak V, Correcher V, Darroudi F, Fattibene P, Gruel G, Guclu I, Horn S, Jaworska A, Kulka U, Lindholm C, Lloyd D, Longo A, Marrale M, Monteiro Gil O, Oestreicher U, Pajic J, Rakic B, Romm H, Trompier F, Veronese I, Voisin P, Vral A, Whitehouse CA, Wieser A, Woda C, Wojcik A, Rothkamm K. Review of retrospective dosimetry techniques for external ionising radiation exposures. Radiat Prot Dosim 147: 573-592; 2011.

Akamine AU, Duchen Silva MA, Saiki M, Vasconcellos MBA, De Andrade SL, Fulfaro R. Determination of uranium in human head hair of a brazilian populational group by epithermal neutron activation analysis. Journal of Radioanalytical and Nuclear Chemistry 271: 607-609; 2007. DOI: 10.1007/s10967-007-0315-X

Birchall A, Puncher M, James AC, Marsh JW, Jarvis NS, Peace MS, Davis K, King DJ. Imba expert ${ }^{\mathrm{TM}}$ : Internal dosimetry made simple. Radiat Prot Dosim 105: 421425; 2003. DOI: 10.1093/oxfordjournals.rpd.a006273

Canu IG, Laurent O, Pires N, Laurier D, Dublineau I. Health effects of naturally radioactive water ingestion: The need for enhanced studies. Environ Health Persp 119: 1676-1680; 2011. DOI: 10.1289/ehp.1003224

EFSA. Sceintific opinion. Uranium in foodstuffs, in particular mineral water. Scientific opinion of the panel on contaminants in the food chain. European food safety authority. The EFSA Journal 1018: 1-59; 2009.

Elish E, Karpas Z, Lorber A. Determination of uranium concentration in a single hair strand by laicpms applying continuous and single pulse ablation. Journal of Analytical Atomic Spectrometry 22: 540-546; 2007. DOI: 10.1039/b617396a

Fattibene P, Duckworth TL, Desrosiers MF. Critical evaluation of the sugar-epr dosimetry system. Appl Radiat Isotopes 47: 1375-1379; 1996.

Fattibene P, Trompier F, Wieser A, Brai M, Ciesielski B, De Angelis C, Monaca SD, Garcia T, Gustafsson H, Hole EO, Juniewicz M, Krefft K, Longo A, Leveque P, Lund E, Marrale M, Michalec B, Mierzwińska G, Rao JL, Romanyukha AA, Tuner H. Epr dosimetry intercomparison using smart phone touch screen glass. Radiat Environ Bioph; 2014. 
Fattibene P, Wieser A, Adolfsson E, Benevides LA, Brai M, Callens F, Chumak V, Ciesielski B, Della Monaca S, Emerich K, Gustafsson H, Hirai Y, Hoshi M, Israelsson A, Ivannikov A, Ivanov D, Kaminska J, Ke W, Lund E, Marrale M, Martens L, Miyazawa C, Nakamura N, Panzer W, Pivovarov S, Reyes RA, Rodzi M, Romanyukha AA, Rukhin A, Sholom S, Skvortsov V, Stepanenko V, Tarpan MA, Thierens H, Toyoda S, Trompier F, Verdi E, Zhumadilov K. The 4th international comparison on epr dosimetry with tooth enamel: Part 1: Report on the results. Radiation Measurements 46: 765-771; 2011.

Finkelstein MM, Kreiger N. Radium in drinking water and risk of bone cancer in ontario youths: A second study and combined analysis. Occupational and Environmental Medicine 53: 305-311; 1996. DOI: 10.1136/oem.53.5.305

Follicle. Hair structure and hair life cycle (accessed 2014-06-24) [online]. Available at: http://www.follicle.com/hair-structure-life-cycle.html.

Gonnen R, Kol R, Laichter Y, Marcus P, Halicz L, Lorber A, Karpas Z. Determination of uranium in human hair by acid digestion and fias-icpms. Journal of Radioanalytical and Nuclear Chemistry 243: 559-562; 2000.

Gustafsson H. Development of sensitive EPR dosimetry methods. Linköping university medical dissertation no. 1044. 2008.

Hallstadius L. A method for the electrodeposition of actinides. Nuclear Instruments and Methods In Physics Research 223: 266-267; 1984. DOI: 10.1016/01675087(84)90659-8

Hervé ML. Dosimétrie d'accident en champ mixte (neutrons, photons) utilisant la spectrométrie par résonance paramagnétique électronique (rpe). In: Faculte de Medecine Paris-Sud. Universite Paris XI; 2006.

Hervé ML, Trompier F, Tikunov DD, Amouroux V, Clairand I. Study of materials for mixed field dosimetry by epr spectroscopy. Radiat Prot Dosim 120: 205-209; 2006.

Holm E. Review of alpha-particle spectrometric measurements of actinides. Int J Appl Radiat Is 35: 285-290; 1984. DOI: 10.1016/0020-708X(84)90070-X

Hutt G, Brodski L, Polyakov V. Gamma-ray dose assessment after the 1994 radiation accident in Kiisa (Estonia): Preliminary results. Appl Radiat Isotopes 47: 13291334; 1996.

International Commission on Radiological Protection (ICRP). Human respiratory tract model for radiological protection. Annals of the icrp 24; 1994.

International Commission on Radiological Protection. Age-dependent doses to members of the public from intake of radionuclides: Part 3 ingestion dose coefficients. Ann icrp 25; 1995.

International Commission on Radiological Protection (ICRP). Individual monitoring for internal exposure of workers. Annals of the icrp 27; 1997.

International Commission on Radiological Protection (ICRP). Human alimentary tract model for radiological protection. Annals of the icrp 36; 2006.

International Commission on Radiological Protection (ICRP). Compendium of dose coefficients based on icrp publication 60. Icrp publication 119. Annals of the icrp 41(Suppl.); 2012.

International Atomic Energy Agency. Use of electron paramagnetic resonance dosimetry with tooth enamel for retrospective dose assessment. IAEATECDOC-1331, Vienna; 2002. 
Isam Salih MM, Pettersson HBL, Lund E. Uranium and thorium series radionuclides in drinking water from drilled bedrock wells: Correlation to geology and bedrock radioactivity and dose estimation. Radiat Prot Dosim 102: 249-258; 2002. DOI: 10.1093/oxfordjournals.rpd.a006093

Ivanovich M, Harmon RS. Uranium series disequilibrium - applications to environmental problems. Oxford: Oxford Science Publications; 1982.

Jia G, Torri G, Magro L. Concentrations of ${ }^{238} \mathrm{U},{ }^{234} \mathrm{U},{ }^{235} \mathrm{U},{ }^{232} \mathrm{Th},{ }^{230} \mathrm{Th},{ }^{228} \mathrm{Th},{ }^{226} \mathrm{Ra}$, ${ }^{228} \mathrm{Ra},{ }^{224} \mathrm{Ra},{ }^{210} \mathrm{Po},{ }^{210} \mathrm{~Pb}$ and ${ }^{212} \mathrm{~Pb}$ in drinking water in italy: Reconciling safety standards based on measurements of gross $\alpha$ and $\beta$. J Environ Radioactiv 100: 941-949; 2009. DOI: 10.1016/j.jenvrad.2009.07.002

Karakirova Y, Lund E, Yordanov ND. Epr and uv investigation of sucrose irradiated with nitrogen ions and gamma-rays. Radiation Measurements 43: 1337-1342; 2008. DOI 10.1016/j.radmeas.2007.10.048

Karpas Z. Uranium bioassay - beyond urinalysis. Health physics 81: 460-463; 2001.

Karpas Z, Paz-Tal O, Lorber A, Salonen L, Komulainen H, Auvinen A, Saha H, Kurttio $\mathrm{P}$. Urine, hair, and nails as indicators for ingestion of uranium in drinking water. Health physics 88: 229-242; 2005a.

Li WB, Karpas Z, Salonen L, Kurttio P, Muikku M, Wahl W, Hollriegl V, Hoeschen C, Oeh U. A compartmental model of uranium in human hair for protracted ingestion of natural uranium in drinking water. Health Phys 96: 636-45; 2009.

Mohagheghi AH, Shanks ST, Zigmond JA, Simmons GL, Ward SLA. A survey of uranium and thorium background levels in water, urine, and hair and determination of uranium enrichments by icp-ms. Journal of Radioanalytical and Nuclear Chemistry 263: 189-195; 2005. DOI: 10.1007/s10967-005-0036-y

Morss LR, Edelstein NM, Fuger J, Katz JJ. The chemistry of the actinide and transactinide elements. Springer; 2011.

Muikku M, Puhakainen M, Heikkinen T, Ilus T. The mean concentration of uranium in drinking water, urine, and hair of the occupationally unexposed finnish working population. Health physics 96: 646-654; 2009. DOI: 10.1097/01.HP.0000345026.98668.c4

Nakajima T. Estimation of absorbed dose to evacuees at pripyat-city using esr measurements of sugar and exposure rate calculations. Appl Radiat Isotopes 45: 113-120; 1994.

Nakajima T. Esr of sugar as a personnel monitor for radiation emergencies. Appl Radiat Isotopes 46: 819-825; 1995.

Nationalencyklopedin. Bokförlaget bra böcker. 1992.

Nazmov V, Reznikova E, Boerner M, Mohr J, Saile V, Snigirev A, Snigireva I, DiMichiel M, Drakopoulos M, Simon R, Grigoriev M. Refractive lenses fabricated by deep sr lithography and liga technology for x-ray energies from 1 kev to 1 mev. AIP Conference Proceedings 705: 752-755; 2004. doi:http://dx.doi.org/10.1063/1.1757905

NCRP. Management of terrorist events involving radioactive material. Recommendations of the national council on radiation protection and measurements. Bethesda, Md.: National Council on Radiation Protection and Measurement; 2001.

Osmond J, Cowart J. The theory and uses of natural uranium isotopic variations in hydrology. 1976. 
Prat O, Vercouter T, Ansoborlo E, Fichet P, Perret P, Kurttio P, Salonen L. Uranium speciation in drinking water from drilled wells in southern finland and its potential links to health effects. Environmental Science and Technology 43: 3941-3946; 2009. DOI: 10.1021/es803658e

Regulla DF, Deffner U. Dose estimation by esr spectroscopy at a fatal radiation accident. Appl Radiat Isotopes 40: 1039-1043; 1989.

Sagstuen E, Theisen H, Henriksen T. Dosimetry by esr spectroscopy following a radiation accident. Health Phys 45: 961-8; 1983.

Shiraishi K. Esr dose estimation of the radiological accident in samut prakarn, thailand using sugar samples and an esr method. Advances in ESR Applications 18; 2002.

Simon R, Buth G, Hagelstein M. The x-ray-fluorescence facility at anka, karlsruhe: Minimum detection limits and micro probe capabilities. Nuclear Instruments and Methods in Physics Research Section B: Beam Interactions with Materials and Atoms 199: 554-558; 2003. http://dx.doi.org/10.1016/S0168-583X(02)01418-0

Swartz HM, Williams BB, Nicolalde RJ, Demidenko E, Flood AB. Overview of biodosimetry for management of unplanned exposures to ionizing radiation. Radiation Measurements 46: 742-748; 2011.

Trompier F, Bassinet C, Wieser A, Angelis CD, Viscomi D, Fattibene P. Radiationinduced signals analysed by epr spectrometry applied to fortuitous dosimetry. Annali dell'Istituto Superiore di Sanita 45: 287-296; 2009.

United Nations Scientific Commitee on the Effects of Atomic Radiation. Sources and effects of ionizing radiation. New York: United Nations; Annex B: Exposure from natural radiation sources; 2000

Wrenn ME, Durbin PW, Howard B, Lipsztein J, Rundo J, Still ET, Willis DL. Metabolism of ingested $\mathrm{u}$ and ra. Health physics 48: 601-633; 1985. DOI: 10.1097/00004032-198505000-00004 


\section{Publications}

The articles associated with this thesis have been removed for copyright reasons. For more details about these see:

http://urn.kb.se/resolve?urn=urn:nbn:se:liu:diva-108892 



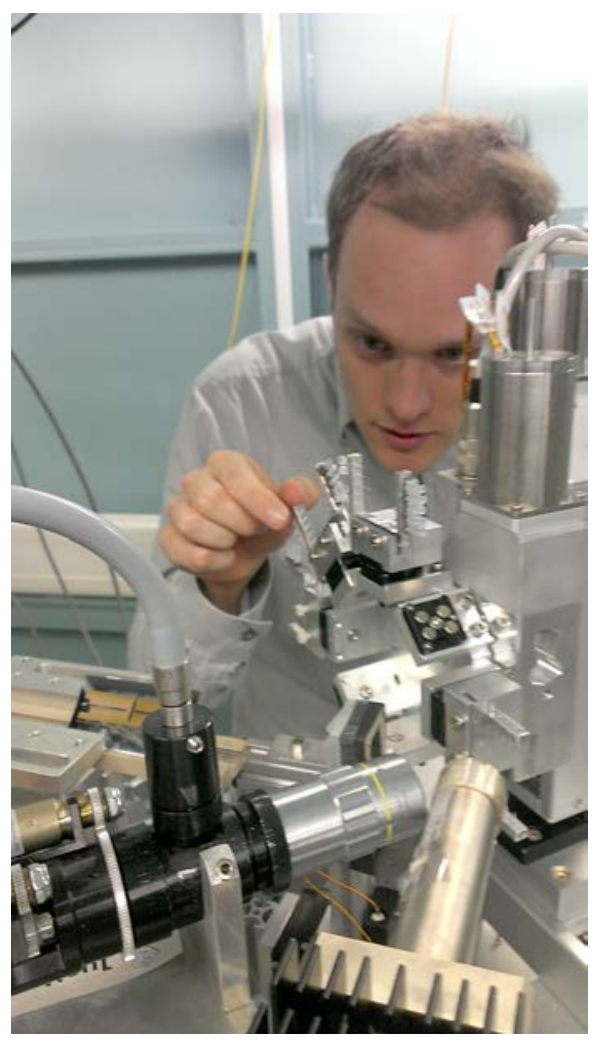

Axel Israelsson graduated in medical radiation physics at Stockholm University in 2008. Since then he has been at Linköping University. This is his doctoral thesis. 